\title{
Fatty acid-based radically polymerizable monomers: from novel polyacrylates to cutting-edge properties
}

\author{
Juliette Lomège, Vincent Lapinte, Claire Negrell, Jean-Jacques Robin, Sylvain Caillol ${ }^{*}$
}

Institut Charles Gerhardt Montpellier UMR 5253, Univ Montpellier CNRS ENSCM, Université de Montpellier, CC1702, Place Eugène Bataillon, 34095 Montpellier Cedex 5, France.

* Correspondence to: S. Caillol (E - mail: sylvain.caillol@enscm.fr)

\begin{abstract}
The increasing price of barrels of oil, the global warming and other environmental problems favour the use of renewable resources to replace the petroleum based polymers used in various applications. Recently, fatty acids (FA) and their derivatives have appeared as one of the most promising candidates to afford novel and innovative biobased (co)polymers because of their ready availability, their low toxicity and their high versatility. However, the current literature mostly focused on FA-based polymers prepared by condensation polymerization or oxypolymerization while only few works have been devoted to radical polymerization due to the low reactivity of FA through radical process. Thus, the aim of this article is to give an overview of (i) the most common synthetic pathways reported in literature to provide suitable monomers from FA and their derivatives for radical polymerization, (ii) the available radical processes to afford FA-based (co)polymers and (iii) the different applications in which FAbased (co)polymers have been used since the last few years.
\end{abstract}

KEYWORDS: Renewable resources; Fatty acids; acrylate monomers; Radical polymerizations; polyacrylates

\section{ABBREVIATION}

$\mathrm{AcFA}=$ acrylic FA derivatives

$\mathrm{AFAD}=$ allylic FA derivatives

AIBN = Azobisisobutyronitrile

$\mathrm{AMO}=$ acrylated methyl oleate 
AsA $=$ ascorbic acid

ATRP $=$ Atom transfer radical polymerization

$\mathrm{BAMO}=$ bromoacrylated methyl oleate monomer

BDDA $=1,4$-butanediol diacrylate

Boc-Phe-HEMA = poly(tert-butyloxycarbonyl phenylalanine methacryloyloxyethyl ester)

$\mathrm{CDP}=4$-cyano-4-(dodecylsulfanylthiocarbony) sulfanypentanoic acid

Cell $=$ cellulose

$\mathrm{CRP}=$ controlled radical polymerizations

DAEMA = dehydroabietic ethyl methacrylate

DCC $=$ dicyclohexylcarbodiimide

DMAP = 4-dimethylaminopyridine hydroxylethyl acrylate

$\mathrm{DMF}=\mathrm{N}, \mathrm{N}-$ Dimethylformamide

DMSO = Dimethyl sulfoxide

DNbpy $=4,4-d i(5-n o n y l)-2,2 '$-bipyridine

$\mathrm{FA}=$ fatty acid

$\mathrm{FAl}=$ fatty alcohol

FAVE $=$ fatty acid vinyl ester

$\mathrm{FE}=$ fatty ester

FRP $=$ Free Radical Polymerization

GMA = glycidyl methacrylate

HEA = hydroxylethyl acrylate

HEMA = hydroxylethyl methacrylate

$\mathrm{kDa}=$ kilodalton

$\mathrm{KOH}=$ potassium hydroxyde

KPS $=$ potassium persulfate

Macro-CTA = macro RAFT agent

MAEO = 2-(methacryloyloxy)ethyl oleate 
MLA = methacrylate linoleic acid

MMA= methyl methacrylate

MOA = methacrylate oleic acid

$\mathrm{P}(\mathrm{M}) \mathrm{A}=$ polyalkyl(meth)acrylate

PASEMA $=$ poly $($ acetylsalicylic ethyl methacrylate

PEGMA $=$ poly $($ ethylene glycol $)$ methyl ether methacrylate

PFAMA $=$ FA-based homopolymers

PLMA $=$ poly $($ lauryl methacrylate $)($ PLMA $)$

PMAEO = poly (methacryloyloxyethyl oleate $)($ PMAEO $)$

PMDETA = N,N,N,N',N"''-pentamethyldiethylenetriamine

$\mathrm{PPD}=$ pour point depressant

PPMI = N-(n-propyl)2-pyridylmethanimine

PSA $=$ pressure-sensitive adhesive

PSAMA $=\operatorname{poly}(2-($ methacryloyloxy $)$ ethyl stearate $)$

RAFT $=$ reversible addition-fragmentation chain-transfer polymerization

SAMA = 2-(methacryloyloxy)ethyl stearate monomer (SAMA)

TBHP = tert-butylhydroperoxide

$\mathrm{Tg}=$ glass transition

$\mathrm{THF}=$ tetrahydrofuran

$\mathrm{TPE}=$ thermoplastic elastomer

$\mathrm{VII}=$ viscosity index improver

$\mathrm{VO}=$ vegetable oil

VOC $=$ organic volatile compounds

$\alpha-\mathrm{MBL}=\alpha$-methylene- $\gamma$-butyrolactone

\section{Introduction}

Historically, vegetable oils (VO) were firstly used as raw materials in the coating industry, especially as drying oils or to provide alkyd resins. ${ }^{1,2}$ For instance, highly unsaturated vegetable oils such as tung (wood) and linseed oil have been mainly used in paints, varnishes 
or coatings as they both contain conjugated double bonds which polymerize easily under air exposition. ${ }^{3,4}$ Today, due to the current environmental and health related issues, the polymer chemists and technological advances in oleo-chemistry have extended the range of application of VO and demonstrated their huge potential to enhance sustainable development. ${ }^{5-8}$ In the spotlight of chemical industry since the last decade, their increasing widespread is attributed to many advantages including a wide global availability, diversity in terms of compositions, a low cost, and mostly a positive environmental impact (e.g low toxicity and ecotoxicity). ${ }^{9} \mathrm{VO}$ are mainly composed of fatty acids (FA) which contain reactive sites, particularly carboxylic acid function and double bonds for unsaturated FA, opening up various possibilities of functionalizations to tailor new biobased monomers. ${ }^{10}$ In some specific VO, such as castor and vernonia oils, which contain respectively hydroxyl and oxirane groups, other synthetic routes can be used for functionalization. ${ }^{11,12}$ Hence, in the last decades, various building blocks and polymers have been developed from VO, including polyurethane, ${ }^{13,14}$ polyester, ${ }^{15-}$ ${ }^{17}$ polyepoxy ${ }^{18}$ and polyamine ${ }^{19}$ by introducing polymerizable moities such as acid, epoxy, amine or alcohol functions on the FA structure. These resulting polymers have found uncountable industrial applications such as plasticizers, ${ }^{20}$ additives for biodiesel ${ }^{21}$, lubricants, ${ }^{22}$ adhesives ${ }^{23}$ or coatings. ${ }^{24}$ Despite the increasing widespread of polymers from VO, most currently available syntheses are dedicated to step growth polymerization and oxypolymerization while only few of them have been devoted to radical (chain growth) polymerization. ${ }^{6,9}$ However, radical processes have many advantages including easy experimental conditions and high versatility toward reaction conditions as they can be performed in bulk, solution or even (micro)emulsion. ${ }^{25}$ Moreover, among the wide available radical processes, controlled radical polymerizations can allow the preparation of well-defined architectures which is not possible with conventional poylcondensation. ${ }^{26}$ Thus, radical polymerization represents a great potential for the preparation of innovative FA-based (co)polymers with promising properties for a broad range of applications. If only a few attempts have been made on FA-polymers resulting from radical polymerization, it is related to the fact that most commonly FA are saturated which makes them unreactive for radical polymerization processes if used as such. Additionally, direct radical polymerization of unsaturated FA is difficult due to the low reactivity of the internal double bonds. The presence of allyl hydrogens, which are good radical traps, associated with the steric hindrance of the aliphatic chains, explain the limited reactivity of FA internal double bonds. Thus, in order to afford more diversified biobased polymers from FA and extent their range of applications, 
numerous and important works were performed by various teams to propose new fatty-acid based radically polymerizable monomers and study them for novel polyacrylates.

Thereby, the aim of this review is to give for the first time an overview on the different chemical pathways which have been reported to functionalize FA and their derivatives into monomers able to undergo effective radical polymerization. The different available processes of radical polymerizations as well as the leading FA-based polymer applications will be also reported in this paper. Thus, the aim of this review is to present both fundamental and applied research (including industrial patents) on the synthesis of fatty acid-acrylates monomers polymers. Their use will be described as building block for material chemistry. Bio-refinery processes and retreatment of biomass will be out of our scope.

Firstly, we report the routes for the synthesis of fatty-acid monomers. Secondly we focus on the different radical polymerization used to yield fatty-based polyacrylates and discuss the various processes. Thirdly, we report various applications and cutting edge obtained properties with these new polymers, with promising developments in the future.

\section{Syntheses of FA-based monomers suitable for radical polymerization}

As previously mentioned, FA and their derivatives contain reactive sites in their structure, including the internal unsaturation or the carboxylic function which can be easily used to graft radical polymerizable moieties through various chemical modifications.

\subsection{From fatty alcohol (FAl) derivatives}

Fatty alcohols (FAl) result mostly from the hydrogenation of FA or fatty esters (FE). ${ }^{27,28}$ Since they contain hydroxyl groups they can be easily functionalized with various (meth)acrylate functions by (trans)esterification (Scheme 1). For instance, Khalkar et al. have successfully synthesized several n-alkyl acrylates by simply reacting equimolar amounts of different FAl (including lauryl, myristyl, palmityl, and stearyl alcohols) with acrylic acid in toluene at $120{ }^{\circ} \mathrm{C}$ in the presence of p-toluenesulfonic acid as catalyst. ${ }^{29}$ Efficient and more eco-friendly alternative method of esterification catalyzed with Novozym 435 lipase (from Candida unfurctica) was also reported for the preparation of acrylate monomers from stearyl and oleyl alcohols. ${ }^{30}$ According to the efficiency of the functionalization, the process was extended to their methacrylate analogues by using methacrylate acid instead of acrylic acid. Additionally, others (meth)acrylate functions have been grafted to the backbone of FAs in the last few years. For instance, Chen et al. prepared various n-alkyl acrylates from lauryl, oleyl, linoleyl, linolenyl alcohols in high yields $(<65 \%)$ by reacting them with an excess of acryloyl 
chloride in the presence of triethylamine. ${ }^{31}$ More recently, Meier et al. used a similar procedure by grafting successfully methacryloyl chloride onto various FAl backbones with different chain lengths. ${ }^{32}$ However, the experimental conditions are not ideal as they require sub-ambient temperature $\left(0{ }^{\circ} \mathrm{C}\right)$, an excess of trimethylamine and methacryloyl chloride which is, in addition, a highly toxic and flammable compound. In the recent years, the octadecyl methacrylate monomer was also synthesized using transterification by reacting methyl methacrylate and a large excess of octadecanol at $90{ }^{\circ} \mathrm{C}$ in the presence of sulfuric acid and hydroquinone. ${ }^{33}$ The different solubilities between octadecyl alcohol and the resulting monomer in methanol allowed an efficient purification leading to $80 \%$ yield. The work was further extended to other fatty alcohols with different chain lengths. ${ }^{34}$ Scheme 1 summarizes the general mechanism of (trans)esterification to afford n-alkyl methacrylates from FAl.

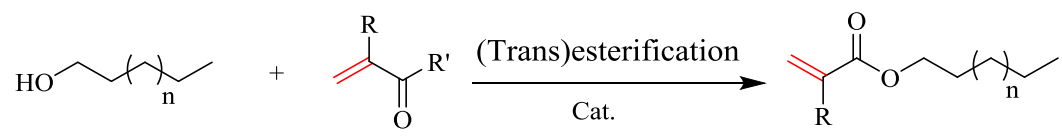

Scheme 1: Synthetic routes for providing (meth)acrylate monomers from $\mathrm{FAl}$ with $\mathrm{R}=-\mathrm{H} ;-\mathrm{CH}_{3}$ and $\mathrm{R}^{\prime}=-\mathrm{OH} ;-\mathrm{Cl}, \mathrm{OR}{ }^{\prime}$

\subsection{From fatty acid (FA) and fatty ester (FE) derivatives}

Besides the conventional (trans)esterification of FAl, other synthetic pathways have been described in literature to functionalize directly FA into reactive monomers by using their available reactive sites including the double bond and the carboxylic acid. All synthetic routes mentioned in this part are summarized in Scheme 2 and Scheme 3 for functionalization of the carbon-carbon double bond and the carboxylic acid, respectively.

\subsubsection{Functionalization of carbon-carbon double bonds}




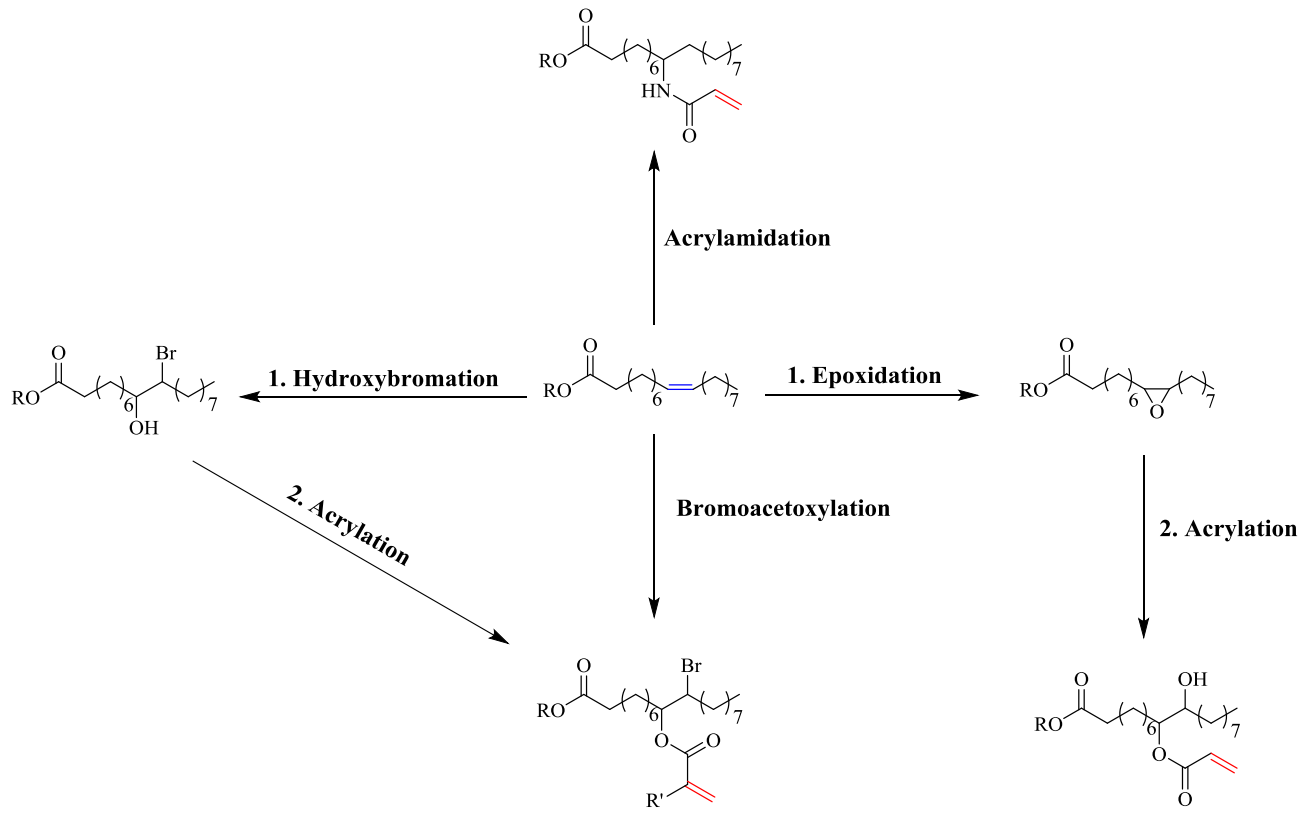

Scheme 2: Illustration of the available synthetic routes for providing suitable FA-based monomers for radical polymerization through double bonds modifications with $\mathrm{R}=-\mathrm{H} ;-\mathrm{CH}_{3}$ and $\mathrm{R}=-\mathrm{H} ;-\mathrm{CH}_{3}$

\section{a) Epoxidation-acrylation}

The most commonly used synthetic routes to add polymerizable function to the carboncarbon double bond of FA and derivatives involves a two-step method based on epoxydation and acrylation. ${ }^{35-39}$ Epoxidation of unsaturations of FA and derivatives can be achieved by the action of peroxides or peracides. Two common reagents used for this purpose are metachloroperbenzoic acid or hydrogen peroxide in the presence of a carboxylic acid, usually acetic $^{40}$ or formic acid ${ }^{41}$ to form a peracid in-situ. Generally, formic acid is preferred over acetic acid as oxygen carrier, related to its high reactivity and since it does not require any catalyst. Then, the epoxidation step is followed by the ring-opening with acrylic acid to yield a $\beta$-hydroxyl acrylate derivative. This synthetic pathway has been reported many times in the last few years with various FA or FE derivatives especially methyl oleate to provide functional monomer for radical polymerization. ${ }^{41-44}$

\section{b) Hydroxybromination and acrylation}

Another two-step method was reported by Eren et al. to functionalize methyl oleate and oleic acid with acrylate function. ${ }^{45}$ In this paper, the authors described an innovative method for hydroxybromination of FA and their derivatives using $\mathrm{N}$-bromosuccinimide/acetone $/ \mathrm{H}_{2} \mathrm{O}$ mixture. After $24 \mathrm{~h}$ at room temperature, high conversions were obtained for methyl oleate and oleic acid with respectively $85 \%$ and $91 \%$ of converted double bonds. Then, the resulting bromohydrin derivatives were acrylated using an acryloyl chloride and high conversions $(<70 \%)$ were obtained after $6 \mathrm{~h}$ at $45^{\circ} \mathrm{C}$. However, the main disadvantage of allt 
these techniques is the necessarily two-step process which is not very attractive on a large scale.

\section{c) Bromoacetoxylation}

In order to develop an easier process to scale-up, Eren et al. have reported a one-step method of acrylation consisting in the simultaneous addition of bromine and acrylate onto the double bond of methyl oleate. ${ }^{46}$ This work was deeply inspired by Jovtscheff's research work which has studied the bromoacetoxylation of various unsaturated fatty compounds such as methyl ricinoleate, oleic acid, methyl oleate, linoleic acid, and methyl linoleate. ${ }^{47}$ The bromoacetoxylation of methyl oleate was achieved using N-bromosuccinimide/acrylic acid at the same time to afford bromoacrylated methyl oleate monomer (BAMO) in high yield (90 $\%)$. Considering the successful method of methacrylation of methyl oleate, the same procedure was followed to provide the methacrylate analogues of BAMO monomer. ${ }^{44}$

\section{d) Acrylamidation}

In addition, the synthesis of acrylamide-based triglycerides has been also used to afford polymerizable monomers through radical process. These reactions are based on the Ritter reaction where the alkene is protonated in the presence of concentrated sulfuric acid to form a carbocation which can react with the nucleophilic nitrogen atom of the nitrile followed by hydrolysis to the corresponding amide. ${ }^{48}$ The first application of Ritter reaction to VO and their derivatives was firstly reported by Roe et al. who grafted various nitrile compounds among which, acrylonitrile in the presence of sulfuric acid. ${ }^{49}$ After 15 minutes at $30{ }^{\circ} \mathrm{C}$, good yields were obtained for the amidostearic acids $(<90 \%)$. The same procedure was used to functionalize other unsaturated FA with acrylonitrile such as erucic or erucastic acids. ${ }^{50}$ More recently, Eren et al. grafted acrylonitrile onto methyl linoleate and achieved $60 \%$ yield after $1 \mathrm{~h}$ of reaction by using the same procedure. ${ }^{51}$

\subsubsection{Chemical modification of FA via ester or carboxylic functions}

Alternative syntheses can be followed to overcome the low reactivity of FA through radical process by using their carboxylic function as reactive site for functionalization instead of the unsaturation of the aliphatic chain. All synthetic routes mentioned in this part are summarized in Scheme 3. 


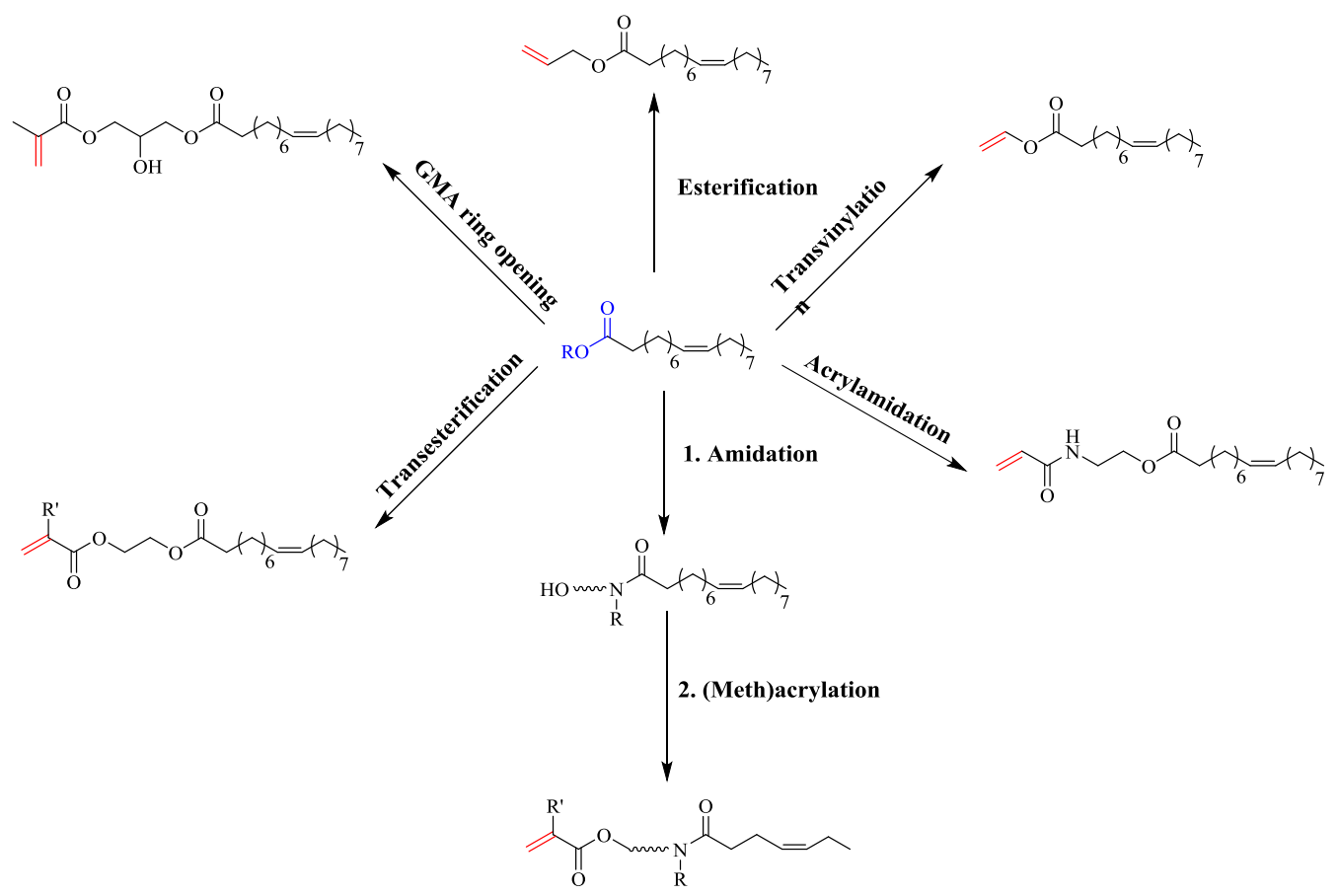

Scheme 3: Illustration of the synthetic routes for providing suitable FA-based monomers for radical polymerization through carboxylic functionalization with $\mathrm{R}=-\mathrm{H} ;-\mathrm{CH}_{3}$ and $\mathrm{R}^{\prime}=-\mathrm{H} ;-\mathrm{CH}_{3}$

\section{a) Transvinylation}

The low reactivity of FA unsaturated aliphatic chains have been also overcome by functionalization with vinyl group introduced by transvinylation. ${ }^{52-55}$ This reaction has been reported several times in literature to prepare fatty acid vinyl esters (FAVEs). ${ }^{56-59}$ This reaction is based on a transition-metal catalyzed transvinylation reaction between vinyl acetate and carboxylic acid where the vinyl interchange is a stereospecific reaction in which the vinyl group is transferred between two acidic moieties. Originally, this equilibrium reaction was carried out in the presence of mercury salts, in combination with strong acid promoters such as sulphuric acid. ${ }^{60}$ However, the use of mercury salts as catalyst is banned today due to their high toxicity and volatility. Thereby, other catalytic systems have been reported to promote transvinylation including palladium ${ }^{54,61}$ or ruthenium complexes. ${ }^{52}$ In addition, Nakagawa et al. proposed an efficient alternative catalyst based on iridium complexes for the transvinylation reaction between carboxylic acid and vinyl acetate. ${ }^{62}$ Thereby, Vilela et al. applied a similar protocol by using safe iridium-based catalyst for the synthesis of FAVES based on oleic and linoleic acids through a one-pot bulk transvinylation in presence of a large excess of vinyl acetate. The resulting FAVEs were obtained in $90 \%$ yield and $50 \%$ yield after 16 and $20 \mathrm{~h}$ of reaction at $100{ }^{\circ} \mathrm{C}$ for vinyl oleate and vinyl linoleate, respectively. ${ }^{63}$ Since then, few reports proposed also iridium complexes as 
alternative catalyst to conventional ruthenium and harmful mercury complexes for the transvinylation reaction between FA and vinyl ester. ${ }^{64}$

\section{b) (Trans)esterification}

A possible approach to prepare FA-based monomers suitable for radical polymerization is the one-step esterification of a FA with the allylic alcohol which has been frequently described in literature. ${ }^{65,66}$ However, in order to ensure high conversion, a significant excess of alcohol and high temperatures must be used. ${ }^{67}$ As a result, different experimental strategies of (trans)esterification were reported in literature in the recent years. For instance, Barbosa et $a l$. have experimented two different processes to afford new allyl and acrylic FA derivatives both from vegetable oils via two-step esterification and transesterification strategies. In the two-step esterification, saturated palmitic acid and a mixture of conjugated FA were first reacted with phosphorus trichloride $\left(\mathrm{PCl}_{3}\right)$ to provide highly reactive $\mathrm{FA}$ acyl chloride derivatives after $1 \mathrm{~h}$ at $55^{\circ} \mathrm{C}$. The resulting derivatives were then mixed with equimolar allyl alcohol for $1 \mathrm{~h}$ to afford a conversion of approximatively $80 \%{ }^{67}$ However, this method required the use of $\mathrm{PCl}_{3}$ which is a highly toxic and corrosive chemical compound. In the transesterification method, a mixture of conjugated FA was reacted with equimolar ethylene glycol in the presence of a catalytic amount of dibutyl tin oxide at $200{ }^{\circ} \mathrm{C}$. This derivative was then esterified at room temperature with acryloyl chloride using trimethylamine as catalyst to achieve an acrylate FA-based monomer in high yield (86 \%) after $5 \mathrm{~h}$ of reaction. ${ }^{68}$ For both cases, the final products were obtained with shorter reaction times than the usual direct esterification of FA with allyl alcohol. More recently, Maiti et al. reported a new method of functionalization involving Steglich esterification of various FA (caprylic, capric, lauric, myristic, palmitic, stearic and oleic acids) to provide partially biobased methacrylate monomers in a one-step method. ${ }^{69,70}$ In this work, an excess of 2-hydroxylethyl methacrylate (HEMA) was reacted with different FA in tetrahydrofuran at room temperature in the presence of dicyclohexylcarbodiimide (DCC) as coupling reagent and 4dimethylaminopyridine (DMAP) as catalyst. After $24 \mathrm{~h}$ of reaction, all resulting methacrylate monomers were obtained in high yields (75-85\%) and suggested that this process of functionalization can be investigated on other unsaturated fatty acids such as linoleic, linolenic, or erucic, etc. However, the use of DCC and DMAP in the Steglich esterification process can limit the scale-up because of their well-known toxicity toward human and environment. Hence, more eco-friendly processes have also been described in the last few years to functionalize FA and their derivatives with polymerizable moities. For instance, Cho 
et al. reported the synthesis of an acrylic-based monomer by transterification of methyl oleate with hydroxylethyl acrylate (HEA) in the presence of the biobased lipase catalysts. ${ }^{71}$ In order to select proper lipase catalysts for this transesterification, different lipases among which Lipozyme RMIM, Lipozyme TLIM, Novozyme-435, and CAL-B were used at several temperatures in toluene (50, 70 and $\left.90{ }^{\circ} \mathrm{C}\right)$. From this study, Novozyme-435 lipase derived from Candida antartica appeared as the best catalyst for the formation of the acrylic monomer with $80 \%$ yield at $90{ }^{\circ} \mathrm{C}$ after $24 \mathrm{~h}$ of reaction. Similar synthetic pathway using enzymatic transesterification of FA and their derivatives by methacrylate moiety has been more recently reported by Kim et al. ${ }^{72}$. In this work, HEMA has been grafted onto the ester group of methyl oleate and methyl laurate in the presence of Candida antarctica lipase $B$ as catalyst. In this study, various solvents and reaction temperatures were tested and the higher yields were obtained when the reaction occurred at $60^{\circ} \mathrm{C}$ in a polar solvent such as toluene (97 $\%$ and $89 \%$ for respectively lauryl methacrylate and oleic methacrylate). Hence, both last reported processes have the main advantage to respect the Green Chemistry principles that promote the replacement of toxic chemical catalyst by safer ones.

\section{c) Acrylamidation}

In order to provide substitutes to petroleum-based monomers in the production of acrylic polymers by radical polymerization, Tarnavchyk et al. have recently developed a new direct one-step acrylamidation approach for converting VO into acrylamide monomers. ${ }^{73}$ For this pathway, direct transesterification of crude soybean oil with $\mathrm{N}$-hydroxyethyl-acrylamide was performed in the presence of catalytic amount of sodium hydroxide. Among various solvents, tetrahydrofuran appeared as a suitable reaction medium for reaching high yields (90\%) which depends on the initial concentration of the reactants and the ratio of catalyst to reactants. Considering the efficiency of the acrylamidation method to functionalize soybean oil into suitable monomer for radical polymerization, the same procedure has been also applied in further work to other VO such as linseed, sunflower and olive oils. ${ }^{74}$ The resulting functional VO contains one acrylic double bond linked to one fatty chain that varies between fully saturated, mono- and polyunsaturated, depending on VO composition. However, this novel synthetic route has not been used yet directly on FE as far as we know even if a monofunctional monomer could provide new linear polymers with promising and tunable properties according to the FE nature. 


\section{d) Amidation and (meth)acrylation}

Another synthetic route based on a two-step method through amidation followed by (meth)acrylation has been recently reported by Yuan et al. to provide monomers for radical polymerization. ${ }^{75}$ In their works, triglycerides of soybean oil were easily converted into Nhydroxyalkyl fatty amides in the presence of various amino alcohols via a mild catalyzed amidation process at $60{ }^{\circ} \mathrm{C}$ with nearly quantitative yields $(95-97 \%)$ without the use of column chromatography and organic solvents. These resulting fatty amides were further involved in esterification with methacrylic anhydride and 4-dimethylaminopyridine as catalyst. After $24 \mathrm{~h}$ of reaction at $60{ }^{\circ} \mathrm{C}$, between 96 and $98 \%$ of methacrylate monomers were obtained. In a further work, Yuan et al. have followed the same procedure with different amino alcohols to provide other monomers for further radical polymerization. ${ }^{76}$ Similar work of amidation and acrylation processes have been reported by Delatte et al. in which soybean oil was functionalized with polymerizable moities via two synthetic routes after amidation: acryloyl chloride in the presence of trimethylamine and direct esterification with acrylic acid. ${ }^{77}$ The resulting soyamide acrylate monomers were obtained in high yields in both cases (99-100 \%). This strategic pathway can be used for any plant oil but also directly with FA or derivatives to afford suitable monomers leading to linear polymers through radical polymerization.

\section{e) Epoxy ring opening}

A new innovative method of FA functionalization through the carboxylic acid into reactive monomer for radical polymerization was proposed by La Scala et al. In this work, oleic acid was reacted in stoichiometric quantities with glycidyl methacrylate (GMA) in the presence of a chromium-(III)-based organometallic compound catalyst (AMC-2). ${ }^{41}$ In this reaction, the carboxylic acid of FA undergoes a simple catalytic addition procedure with the epoxide group of GMA. In further study, the same protocol of (meth)acrylation was applied successfully to the 9-10 dibromo stearic acid. ${ }^{78}$ Additionally, Dey et al. also worked on this "ring-opening and esterification" strategy with GMA on other FA than oleic acid including lauric, myristic, stearic and palmitic acids. ${ }^{79}$ Novel FA dimer-based vinyl ester monomer was also prepared through the ring-opening of GMA with dimer fatty acids as starting materials. ${ }^{80}$ In this work, the effect and the amount of the catalyst have been studied as well as the temperature of reaction. It was demonstrated that the optimal conditions were performed at $115{ }^{\circ} \mathrm{C}$ in dioxane using $0.5 \%$ of benzyltriethylammonium chloride as catalyst during 120 minutes. These conditions allowed to achieve good yield (90\%) with a moderate monomer 
viscosity. More recently, Moreno et al. have also employed the addition of GMA over oleic acid to prepare a methacrylated structure in bulk without any purification. It was demonstrated that with 0.1 wt. $\%$ of AMC- 2 catalyst the functionalization was far from completion after $24 \mathrm{~h}$ while with $0.5 \%$, good yields were obtained. ${ }^{81}$ The work was then extended to the successful functionalization of linoleic acid. ${ }^{82}$

\subsection{Conclusion}

In the last recent years, many synthetic pathways have emerged to provide a wide choice of suitable monomers for radical polymerization starting from saturated or unsaturated FA and their derivatives. The main advantage of using an unsaturated FA to graft polymerizable function is that the resulting monomer structure exhibits two types of double bonds. The acrylic, vinylic... groups allows the monomer to be involved in radical polymerization and generate formation of linear polymers containing unsaturated aliphatic chains hanging off the main polymer chain, since internal double bonds are known to have a low reactivity through radical polymerization. As a result, the remaining double bonds may be available for oxidative cross-linking or further post-functionalization to confer various properties to the polymer. Considering the growing interest in providing new biobased (co)polymers with innovative macrostructures, different processes of radical polymerization have been performed on FA-based monomers including conventional radical polymerization and various controlled polymerizations with a broad range of reaction conditions.

\section{Radical polymerizations processes \\ 3.1. Conventional Free Radical Polymerization (FRP)}

Conventional Free Radical Polymerization (FRP) is the most widely employed radical process in the industry to prepare (co)polymers for several reasons: i) FRP is easy to carry out without stringent process conditions, ii) it can be achieved for a large range of reaction temperatures and iii) it can be performed with a wide range of monomers. ${ }^{83}$ Among them, monomers from FA and their derivatives have been involved several times in radical polymerization with different conditions including bulk, solution or aqueous media to provide biobased (co)polymers with innovative structures.

\subsubsection{Bulk polymerization}

Among all radical processes, bulk polymerization offers the simplest and more environmental friendly method of polymerization since no solvent is required. Indeed, the reaction mixture contains only the monomer in which the initiator and the resulting polymer 
are soluble and most often, does not require purification. However, according to the literature, this may not be the most suitable method for FA-based monomers. For instance, Eren et al. have tried to homopolymerize a bromoacrylated methyl oleate (BAMO) through bulk polymerization but they have observed only limited monomer conversion (55\%) after $24 \mathrm{~h}$ at $70{ }^{\circ} \mathrm{C}$ (Scheme 4 , a). ${ }^{84}$ This result has been related to the high viscosity of the system which decreases the mobility of radicals and thus may lower the rate of polymerization. In the same work, they have also studied the bulk copolymerization of 35 wt. \% of BAMO with methyl methacrylate (MMA) at $50{ }^{\circ} \mathrm{C}$ and vinyl acetate at $65{ }^{\circ} \mathrm{C}$ and similar observations were noticed (Scheme 4, b, c). Vinyl acetate based copolymer was a highly viscous oil which was obtained with low conversion (40\%) while the copolymerization of MMA with BAMO gave soft solid polymers that did not dissolve in common solvents. Auto-acceleration, also called Trommsdorff effect is well known to induce local overheating during highly exothermic polymerization as well as the rapid increase of viscosity and thus may be the explanation of the crosslinking of MMA copolymer. ${ }^{85}$ The resulting number average molecular weights for homo- and copolymers ranged from 20 to $35 \mathrm{~kg} / \mathrm{mol}$. These low molecular weights were related to the chain transfer to the bromine group of BAMO.

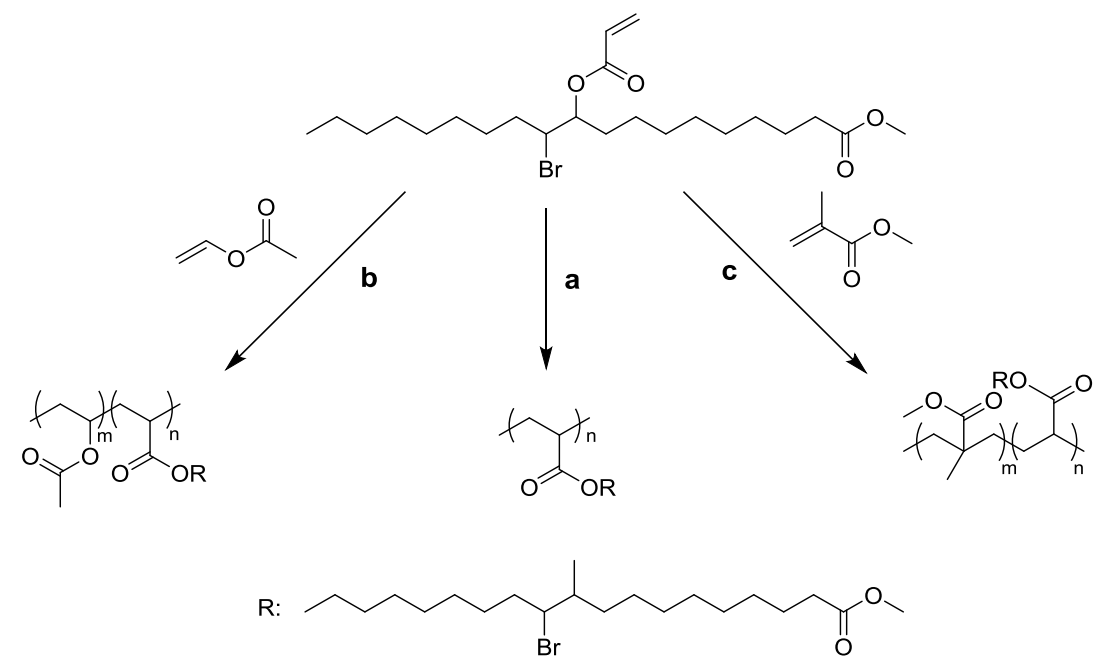

Scheme 4: Bulk (a) Homopolymerization of BAMO at $70{ }^{\circ} \mathrm{C}$, (b) Copolymerization with vinyl acetate at $65^{\circ} \mathrm{C}$, (c) Copolymerization with methyl methacrylate at $50{ }^{\circ} \mathrm{C}$ in presence of azobisisobutyrinitrile $(\mathrm{AIBN})$ initiator

Further works performed by the same research team have confirmed the difficulty to carry out bulk polymerization on FA-based monomers. ${ }^{51}$ Indeed, their study has shown that the bulk homopolymerization at $75{ }^{\circ} \mathrm{C}$ of methyl linoleate and methyl oleate acrylamide adducts also gave soft insoluble solids mainly due to Trommsdorff effect which induced the crosslinking of the homopolymers. Furthermore, in Eren et al. studies, as monomer 
conversions were never total through bulk polymerization, they required further purification in harmful solvent such as methanol to remove unreacted monomers. Consequently, considering the various disadvantages of bulk polymerization toward viscous FA-based monomers, this process was not scaled up.

\subsubsection{Solution polymerization}

Most of the researches are focused on polymerization in solution as it can easily overcome both problemq of heat dissipation and handling of viscous melts. Thereby, FAbased polymers have been mainly achieved through solution FRP in the last few years. ${ }^{86-88}$ Monomers derived from FA are generally polymerized in apolar solvents in which they have a good affinity due to their long aliphatic chains, such as benzene ${ }^{89}$ but also less toxic solvents such as toluene, ${ }^{90}$ xylene,${ }^{91}$ tetrahydrofuran (THF), ${ }^{70}$ or dioxane.$^{51}$ The most widely used FA derivatives involved in FRP solution are currently those containing (meth)acrylate or acrylamide functions due to their good reactivity through radical process despite their long alkyl chain. ${ }^{75,76}$ For instance, Tarnavchyk et al. described the successful FRP solution of a FA-based acrylamide derived from soybean oil by using toluene/AIBN as solvent/thermal initiator system at $60{ }^{\circ} \mathrm{C}$. After $7 \mathrm{~h}$ of reaction, the resulting linear polymer was achieved with $85 \%$ of conversion and a number average molecular weight of $26 \mathrm{~kg} / \mathrm{mol}$ with a dispersity of $1.8 .^{74}$ Besides FA-based (meth)acrylate or acrylamide monomers, other structures have been also involved in FRP solution among which FA derivatives bearing allylic functions. ${ }^{57,65}$ However, such monomers have demonstrated some reluctance to undergo radical polymerization. ${ }^{63}$ For instance, Vilela et al. reported the homopolymerization in toluene of vinyl monomers bearing long chains from oleic and linoleic acid in the presence of BPO initiator but only low monomer conversions of 50 and $10 \%$ were achieved, respectively. Furthermore, only low polymer molecular weights were reached with 4 and $6 \mathrm{~kg} / \mathrm{mol}$, respectively. These results have been related to the low reactivity of the allylic function through radical polymerization coupled with the presence of conjugated unsaturations which promoted chain transfer due to the allylic termination. ${ }^{57}$ This result has been confirmed by Barbosa et al. who have shown that aliphatic double bonds are more likely to be consumed during polymerization in unsaturated FA-based monomers containing allylic double bonds than those containing acrylic ones since they have a considerable higher reactivity through radical process. ${ }^{92}$ In the current literature, the saturated FA-based monomers have shown a better ability to polymerize than their unsaturated analogous because no chain transfer can occur in their aliphatic chains. ${ }^{66}$ 
Nevertheless, even if free solution radical polymerization appears as a simple method to provide various biobased (co)polymers from FA, the majority of the solvents used to properly dissolve FA-based monomers and their resulting polymers are harmful solvents. Additionally, the purification of the FA-based (co)polymers is usually performed in methanol or hexane which are both non eco-friendly solvents. ${ }^{72,84,87}$ However, the replacement of organic solvent is strongly advisable to meet the current environmental regulations.

\subsubsection{Macroemulsion polymerization}

An alternative approach is based on the polymerization in dispersed aqueous media (emulsion or suspension) as a benign process to keep the environmental benefits of using FAmonomers. Additionally, emulsion polymerization allows an easy heat removal due to the high capacity of the water to dissipate heat. As far as we know, Chen and Bufkin were among the firsts to polymerize FA-based monomers through emulsion process. ${ }^{31}$ They have prepared high conversion emulsion cross-linkable polymers by using a small amount (up to 8 wt. \%) of acrylated FA-based comonomers with conventional ethyl and methyl acrylates. The increasing amount of FA promoted the decrease of the resulting copolymer molecular weights which has been confirmed in other studies on the subject. ${ }^{93}$ These results were confirmed in further works. Acrylated methyl oleate (AMO) monomer synthesized by Bunker et al. was homopolymerized through emulsion polymerization but resulted in low conversion and low molecular weight polymers. ${ }^{94}$ Indeed, the polymerization of extremely low water -soluble monomers, such as FA-based monomers, is very difficult through conventional emulsion as the diffusion monomers in the aqueous medium is required. ${ }^{95}$ Thus, to promote the emulsion polymerization of AMO, Bunker et al. used acrylic acid as highly water-soluble comonomer. ${ }^{94}$ Even if high number average molecular weight of polymer $\left(10^{6} \mathrm{~kg} / \mathrm{mol}\right)$, high conversion (91\%) and moderate latex solid content (30\%) were obtained, no calculation of reactivity ratio between monomers were specified which could confirmed that the (co)polymers were not only the result of acrylic acid homopolymerization. Additionally, the emulsion polymerization of FA-based monomers suffers from several drawbacks including the high amount of surfactant required (15 wt. \%) and a low polymerization rate inducing a long reaction time $(18 \mathrm{~h})$.

In addition to this work, Jensen et al. have studied the emulsion copolymerization of AMO with styrene in order to evaluate the influence of AMO content (5-30 wt. \%) on polymerization rate. ${ }^{96}$ Their results have shown that low AMO contents (5-15 wt. \%) promoted high monomer conversions (close to 100\%) whereas high AMO contents (15-30 wt. 
$\%)$ entailed induction time, lower monomer conversions or even no polymerization at all. These observations have been, once again, related to the low AMO solubility in water which induced a decrease in particle nucleation and thereby to a drastic reduction of the total number of radicals. This drawback was overcome by using higher initiator concentrations but thus induced copolymers with lower molecular weights. Hence, according to the amount of initiator, the copolymers average molecular weights ranged from 39 to $280 \mathrm{~kg} / \mathrm{mol}$ with a dispersity ranging from 2 to 4 . Moreover, since polymers of very high molar masses might have strong limitations for their application as they will require a lot of energy during their processing, the use of FA-based monomers in the synthesis of copolymers with tailored molar masses through emulsion polymerization processes appeared as a very promising solution. ${ }^{97}$ For instance, Jensen et al. investigated the emulsion copolymerization of vinyl pivalate with various contents of methacrylated methyl oleate to provide copolymers with tunable and lower average molecular weights than the vinyl pivalate homopolymer. ${ }^{97}$

\subsubsection{Miniemulsion polymerization with lipidic droplets}

In order to overcome the low-solubility of FA monomers in water, Bunker et al. have also experimented miniemulsion radical polymerization on AMO and afforded polymer with low glass transition temperature $\left(-48{ }^{\circ} \mathrm{C}\right) .{ }^{43}$ This process revealed a complete monomer conversion in shorter reaction time than conventional emulsion polymerization $(1 \mathrm{~h}$ instead of $18 \mathrm{~h}$ ) and required a lower amount of surfactant ( $2 \mathrm{wt}$. \% instead of $15 \mathrm{wt}$. \%). The advantage of this process is that the miniemulsion polymerization mainly occurs in the monomer droplets, after an ultrasonification step, whereas in conventional emulsion polymerization, the monomer has to be transported through the aqueous phase (so a minimum water solubility is required) from monomer droplets to the growing polymer particles where the polymerization takes place. ${ }^{98}$ Considering the advantage of miniemulsion over emulsion for highly hydrophobic monomers, the research group of Moreno has mainly used this process to produce polymers entirely based on fatty acid-based monomers from oleic and linoleic acids (Figure 1). ${ }^{81,99,100}$ 


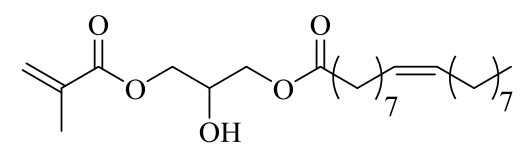

Methacrylated Oleic Acid (MOA)<smiles>C=C(C)C(=O)OCC(O)COC(=O)CC=CCCC</smiles>

Methacrylated Linoleic Acid (MLA)

Figure 1: Monomers derived from FA

Both methacrylated oleic (MOA) and methacrylated linoleic acid monomers (MLA) were homopolymerized through miniemulsion at $70{ }^{\circ} \mathrm{C}$ using two types of initiator among which, the thermal potassium persulfate initiator (KPS) and the redox initiator pair tertbutylhydroperoxide/ascorbic acid (TBHP/AsA) at different amounts (0.5-1.5 wt. \%). ${ }^{82}$ Optimal monomer conversions were achieved by using $1 \%$ wt. of TBHP/AsA (Figure 2). However, if high monomer conversions were reached for both cases, it can be clearly observed that the polymerization rate of MLA was much slower than MOA. Additionally, various polymer molecular weights were observed by varying the amount of initiator. MOAbased polymers have much higher molecular weights than those of MLA-polymers, ranging respectively from 27 to $110 \mathrm{~kg} / \mathrm{mol}$ for MOA and from 16 to $45 \mathrm{~kg} / \mathrm{mol}$ for MLA.
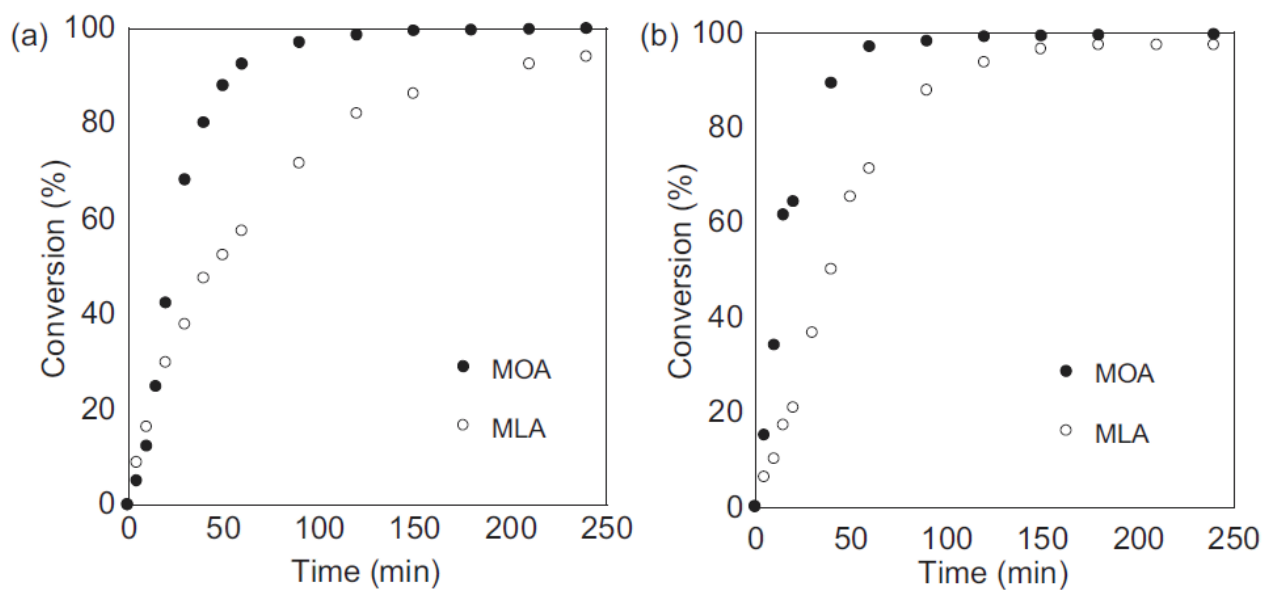

Figure 2: Kinetics of MLA and MOA polymerizations with $1 \%$ of KPS (a) and with 1.5 wt. \% (b) TBHP/AsA

The presence of labile allylic hydrogens in the linoleic acid backbone may promote chain transfer to polymer through abstraction of the allylic hydrogen and thus induce low polymer molecular weights. Indeed, as the resultant linoleic-acid-derived radical from 
hydrogen abstraction is stabilized by conjugation with the internal unsaturations, it has an impact on the kinetics (Scheme 5).

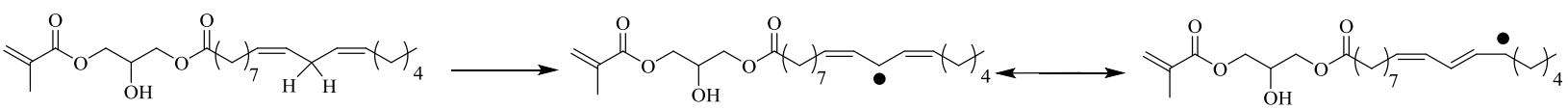

Scheme 5: Mechanism of hydrogen abstraction in the MLA and radical stabilized structures

In further work, Moreno et al. have optimized the miniemulsion polymerization by reacting the residual oleic acid (after MOA synthesis ${ }^{101}$ ) with $\mathrm{KOH}$ to generate in situ surfactant. ${ }^{102}$ High conversions were achieved (close to $100 \%$ ) when the appropriate $\mathrm{OH} / \mathrm{COOH}$ ratio was used. Indeed, it was found that when the $\mathrm{KOH}$ amount increased, the droplet size decreased until a certain ratio at which droplets start to aggregate. This effect was promoted at high solid content because the inter-droplet spacing was small which induced an increase in ionic strength and thus, coagulation. Considering the efficiency of this "in-situ surfactant miniemulsion", it could be easily extended to various other FA-based monomers. In their last study, Moreno et al. have also reported the miniemulsion copolymerization of MOA monomer with $\alpha$-methylene- $\gamma$-butyrolactone ( $\alpha$-MBL) which is also a biobased monomer (Scheme 6). ${ }^{100}$

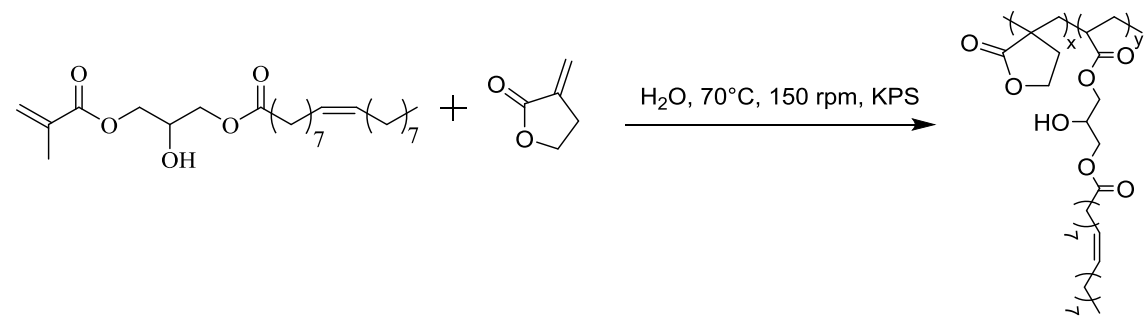

Scheme 6: Copolymerization of $\alpha$-methylene- $\gamma$-butyrolactone and methacrylated oleic acid

The main interest of this monomer relies on its cyclic structure analogous to petrosourced methyl methacrylate as well as on its high glass transition temperature. Thus, copolymers with tunable transition temperatures ranging from $-2{ }^{\circ} \mathrm{C}(0 \mathrm{wt} . \%$ of $\alpha-\mathrm{MBL})$ to $54{ }^{\circ} \mathrm{C}(25 \mathrm{wt} . \%$ of $\alpha-\mathrm{MBL})$ were afforded by incorporating different ratios of $\alpha$-MBL into the copolymer structures. High conversions (close to 100\%) have been achieved and increased with the amount of $\alpha$-MBL. The resulting copolymers exhibited average molecular weights ranging from 110 to $230 \mathrm{~kg} / \mathrm{mol}$. These studies showed a slight lower reactivity of $\alpha$-MBL than MOA, resulting in a random copolymer, with a composition enriched in MOA at the beginning of the 
reaction. Thereby, miniemulsion (co)polymerization appears as more appropriate for highly hydrophobic monomers as well as a promising eco-friendly process to afford novel biobased (co)polymers based on FA and their derivatives.

\subsubsection{Photopolymerization}

Considering the growing interest for eco-friendly polymerization routes, photopolymerization has recently received considerable attention in the synthesis of biobased polymers. $^{103}$ Indeed, radiation curing technologies provide several economic and environmental advantages over usual thermal polymerization such as a fast-curing, cost efficiency, room temperature reaction, non-polluting and solvent-free systems. Various polymers from acrylated modified VO including castor oil, ${ }^{104}$ sunflower oil ${ }^{36}$ and soybean oil $^{105,106}$ have already been successfully obtained in high yield through UV-curing process to provide highly crosslinkable materials.

Several authors have also applied this photopolymerization process to FA-based monomers. For instance, Mhanna et al. reported the synthesis of eight FA-based monomers from stearic and undecylenic acids bearing dimethacrylate functions and involved them into photopolymerization using 2-hydroxy-2-methyl-1-phenyl-propan-1-one as photoinitiator (Scheme 7, A). ${ }^{107}$ After optimization of some parameters such as initiator concentration and light intensity (I), all monomers were polymerized in high conversions $(<90 \%)$ in less than 600 seconds by using $3 \mathrm{wt}$. $\%$ of initiator and a light intensity of $130 \mathrm{~mW} \mathrm{~cm}^{-2}$. Acrylated and methacrylated derivatives exhibited a similar behavior under UV-irradiation and provided high crosslinked polymers as confirmed by the measurement of gel content (96-100\%). The resulting materials also showed promising properties including high thermal stability close to those measured for classical UV-cured acrylates with temperatures corresponding to 5\% weight loss temperature value higher than $300{ }^{\circ} \mathrm{C}$. However, materials derived from undecylenic acid-based monomers showed highest thermal stability and also highest hardness due to the participation of terminal unsaturation in the crosslinking process inducing highest degree of cohesion and rigidity and absence of dangling chain. Additionally, compared to the hardness of current UV-cured epoxy acrylates, FA-based materials are more flexible and this flexibility can be easily modulated according to the chain length of the FA. 
(A)<smiles>[R]C(=C)C(=O)OCC(COC([R])=O)OC(=O)C([R])=C</smiles><smiles>CC(C)(O)C(=O)c1ccccc1</smiles>

$365 \mathrm{~nm}, \mathrm{I}=130 \mathrm{~mW} \mathrm{~cm}{ }^{-2}$

Cross-linked polymers

room temperature

(B)

$$
\begin{aligned}
& \mathbf{1}\left(\mathrm{R}=-\mathrm{C}_{10} \mathrm{H}_{29}, \mathrm{R}^{\prime}=-\mathrm{H}\right) \\
& \mathbf{2}\left(\mathrm{R}=-\mathrm{C}_{10} \mathrm{H}_{29}, \mathrm{R}^{\prime}=-\mathrm{CH}_{3}\right) \\
& \mathbf{3}\left(\mathrm{R}=-\mathrm{C}_{17} \mathrm{H}_{35}, \mathrm{R}^{\prime}=-\mathrm{H}\right) \\
& 4\left(\mathrm{R}=-\mathrm{C}_{17} \mathrm{H}_{35}, \mathrm{R}^{\prime}=-\mathrm{CH}_{3}\right)
\end{aligned}
$$

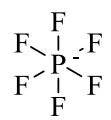

Cross-linked polymers

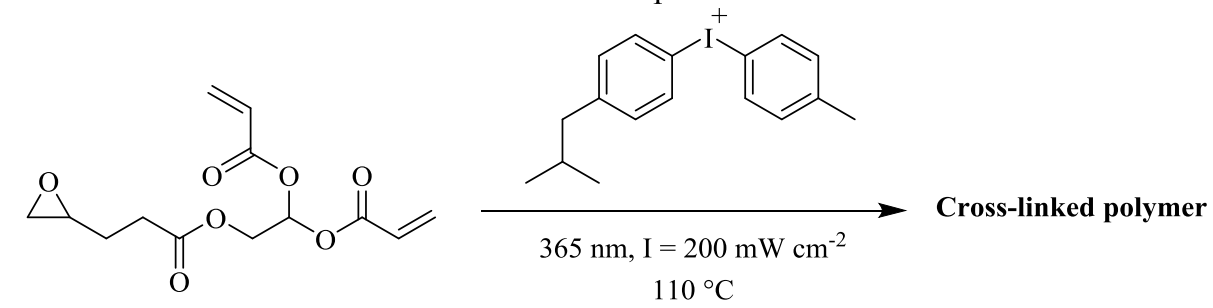

Scheme 7: (A) Photopolymerization of di(meth)acrylated FA-based monomers; (B) hybrid epoxy/diacrylated FA-based monomer

In further studies, the same research group photopolymerized an innovative hybrid epoxy/diacrylated monomer based on undecylenic acid using 4-methylphenyl-4-(2methylpropyl)phenyliodonium hexafluorophosphate as initiator at $110{ }^{\circ} \mathrm{C}$ (Scheme 7, B). ${ }^{108}$ Complete conversion of acrylates was achieved in less than 100 seconds by using optimized conditions including $5 \%$ wt. of initiator and a light intensity of $130 \mathrm{~mW} . \mathrm{cm}^{-2}$. In addition, the low swelling ratio (4.3\%) and high König pendulum hardness value (177) corroborated with the high crosslink density of the resulting polymers. Once again, those results showed the high potential of FA-based monomers for producing promising cross-linkable materials.

However, the preparation of linear polymers through photopolymerization has been much less reported in literature. Among the few reported studies, Eren et al. photopolymerized the bromoacrylated methyl oleate (BAMO) by using 2,2-dimethoxy-2phenyl-acetophenone as initiator. ${ }^{84} \mathrm{~A}$ minimum of dichloromethane was required in order to avoid the increasing viscosity of the system. After 30 minutes of exposure of UV-Vis lamp at $366 \mathrm{~nm}$ at room temperature, $20 \%$ of homopolymers were already achieved while $55 \%$ of monomer conversion was reached through bulk polymerization after $24 \mathrm{~h}$ at $70{ }^{\circ} \mathrm{C}$. Additionally, copolymers were also successfully achieved through photopolymerization with high polymerization rates by reacting BAMO with comonomers at $35 \mathrm{wt}$. \% including methyl methacrylate, styrene and vinyl acetate. The number average molecular weight of homopolymers and copolymers ranged from 20 to $35 \mathrm{~kg} / \mathrm{mol}$. More recently, Walther et al. have synthesized various (meth)acrylated methyl oleates substituted either by bromo or 
hydroxy groups along the fatty chain and photopolymerized them by using the (diethylgermanediyl)bis[(4-methoxyphenyl)methanone] as photoinitiator at $40{ }^{\circ} \mathrm{C}$ (Scheme 8). ${ }^{44}$ This latter has already showed an excellent capability and high initiation efficiency in radical polymerization according to Norrish-Type I cleavage. ${ }^{109}$

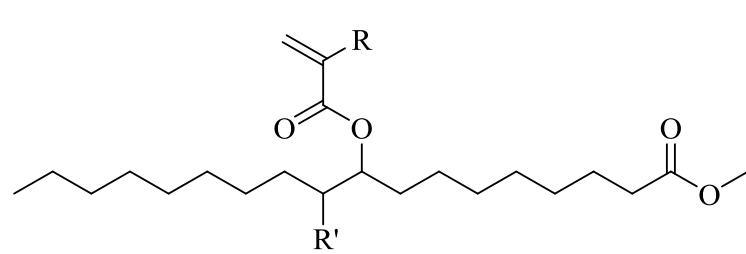

$1\left(\mathrm{R}=-\mathrm{H} ; \mathrm{R}^{\prime}=-\mathrm{OH}\right)$

$2\left(\mathrm{R}=-\mathrm{CH}_{3} ; \mathrm{R}^{\prime}=-\mathrm{OH}\right)$

$3\left(\mathrm{R}=-\mathrm{H} ; \mathrm{R}^{\prime}=-\mathrm{Br}\right)$

$4\left(\mathrm{R}=-\mathrm{CH}_{3} ; \mathrm{R}^{\prime}=\mathrm{Br}\right)$

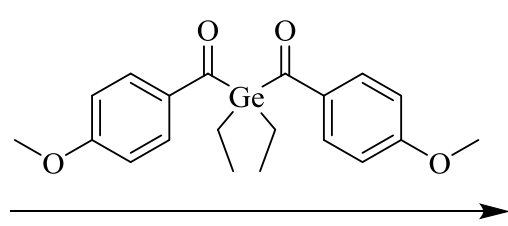

$365 \mathrm{~nm}, \mathrm{I}=350 \mathrm{~W} \cdot \mathrm{cm}^{-2}$

$40{ }^{\circ} \mathrm{C}$

Scheme 8: Photo-initiated polymerization of (meth)acrylated methyl oleate

The study demonstrated that monomers bearing functional group, and especially hydroxyl-substituted monomers, presented a higher photo-reactivity than commercial lauryl (meth)acrylate. These results underlined the high potential of FA-based monomers in curing photopolymerization applications. In summary, as monomers made from FA have become a topic of high interest since in the last few years, the photopolymerization appears as an encouraging solution to afford novel biobased linear or crosslinked polymers through an environmental and friendly process of radical polymerization.

\subsection{Controlled polymerization over FA-based monomers}

Nevertheless, even if many FA-based copolymers have been afforded through various FRP conditions, this radical process has major limitation including the poor control over the polymerization. Controlled radical polymerizations (CRP) have revolutionized polymer science by enabling the preparation of well-defined polymers with controlled molecular weights, narrow dispersities, well-defined compositions, designed architectures, and sitespecific functionality through radical process. ${ }^{26}$ The details of the CRP mechanisms are very well described in recent reviews. ${ }^{110}$ 


\subsubsection{Atom transfer radical polymerization (ATRP) of FA-based monomers}

\section{a) Suitable catalyst for ATRP of monomers with long aliphatic chains}

The ATRP process of polymerization has been proved to be effective for the polymerization of most (meth)acrylate monomers with short side groups. However, considering the bulky structure and the high hydrophobicity of monomers with long alkyl chains, some parameters in the polymerization process required optimization. As far as we know, the Matyjaszewski group was the first to report the successful ATRP polymerization of lauryl acrylate with a suitable choice of ligands for the Cu-based catalyst. ${ }^{111}$ In their work, N,N,N,N',N"''-pentamethyldiethylenetriamine (PMDETA) was firstly tested as ligand but the poor compatibility between the catalytic complex and the monomer/polymer involved heterogeneity and no solvent was found to be enough suitable for both compounds. In the same study, Matyjaszewski et al. used toluene for properly dissolving the highly hydrophobic monomer and replaced PMDETA with 4,4-di(5-nonyl)-2,2'-bipyridine (DNbpy) which is more compatible with lauryl acrylate. $\mathrm{CuBr} / \mathrm{dNbpy}$ catalyst system allowed to achieve narrowly distributed polymers with pre-defined molecular weights. This latter catalyst was successfully applied to the ATRP polymerization in xylene at $90{ }^{\circ} \mathrm{C}$ of both stearyl acrylate and methacrylate. ${ }^{12,113}$ However, dNbpy is not commercially available, difficult to prepare and requires a distillation purification using a Kugelrhor apparatus under high vacuum $\left(10^{7}\right.$ Torr). ${ }^{114}$ As a result, other ligands are easier to prepare and able to dissolve efficiently $\mathrm{CuBr}$ in non-polar solvent using $\mathrm{N}$-(n-octyl)-2-pyridylmethanimine/ $\mathrm{CuBr}^{115}$ and $\mathrm{N}$-(n-propyl)2pyridylmethanimine (PPMI)/CuBr. ${ }^{116}$ Nevertheless, for long alkyl side chains and (meth)acrylates such as stearyl methacrylate, PPMI was not sufficiently hydrophobic to allow a good compatibility with the monomer inducing low monomer conversion $(<32 \%)$ and only a poor control of polymerization. ${ }^{117}$

Although PMDETA was firstly reported as an unsuitable ligand for the polymerization of long alkyl (meth)acrylate monomers, $\mathrm{Xu}$ et al. claimed satisfactory control ATRP of LMA using $\mathrm{CuCl} / \mathrm{PMDETA}$ in DMF at $110{ }^{\circ} \mathrm{C}$ with the synthesis of well-defined polymers with narrow dispersity $(<1.5)$ in high conversions $(80 \%) .{ }^{87}$ Interestingly, Chatterjee et al. reported an innovative catalyst system based on the PMDETA ligand with a highly hydrophobic quaternary ammonium (Aliquat 336). ${ }^{118}$ This combination of both commercial chemicals allowed a perfect solubility of the catalytic complex even in pure lauryl or stearyl methacrylate at $35{ }^{\circ} \mathrm{C}$ giving a good control to the ATRP polymerization. This process can be considered as a "green" polymerization since renewable monomers were used, no solvent was 
required, high conversions were achieved using only low temperature. Figure 3 summarizes the different catalyst systems used for the ATRP polymerization of long alkyl methacrylate chains.

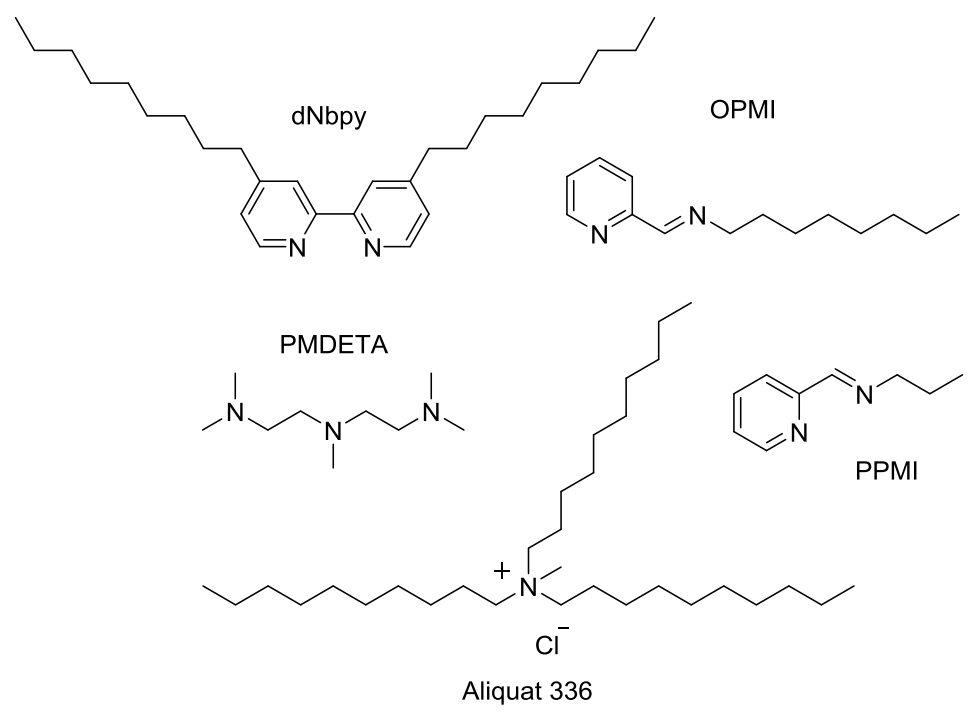

Figure 3: Chemical structure of ligands and hydrophobic quaternary ammonium used for ATRP polymerization of FA-based monomers

Recently, Meier et al. optimized the protocol of Chatterjee et al. by increasing the amount of ligand to polymerize various methacrylate monomers with different FA chain lengths of pending alkyl group from $\mathrm{C}_{10}$ to $\mathrm{C}_{18}$ (Scheme 9). ${ }^{119}$ The resulting homopolymers were obtained in high conversions $(<90 \%)$ and, except for poly(stearyl acrylate), all homopolymers were characterized by a narrow dispersity $(<1.4)$ in reduced reaction times (Table 1) The broad dispersity of the poly(stearyl acrylate) has been easily explained since its melting point was above the reaction temperature and induced the precipitation of the polymer during the polymerization. The polymer melting temperatures $\left(T_{m}\right)$ were increased from -40 to $19{ }^{\circ} \mathrm{C}$ with the increasing length of the pendent alkyl chain contained in the polymer structure.

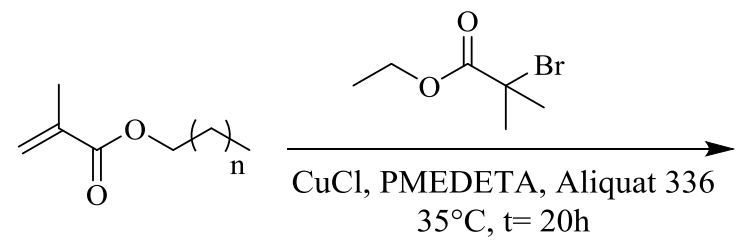<smiles>CCOC(=O)C(C)(C)CC(C)(C)C(=O)OCC</smiles>

Scheme 9: Synthesis of poly(methacrylate)s with different alkyl chain lengths via ATRP polymerization at $35^{\circ} \mathrm{C}$ 
Table 1: SEC characterizations of poly(methacrylate)s. The SEC was calibrated with narrow poly(methyl methacrylate) standards

\begin{tabular}{cccc}
\hline Monomers (alkyl chain lengths) & $\mathbf{M}_{\mathbf{n}}(\mathbf{S E C})(\mathbf{g} / \mathbf{m o l})$ & $\mathbf{D}$ & $\mathbf{T}_{\mathbf{m}}\left({ }^{\circ} \mathbf{C}\right)$ \\
\hline Capric $\left(\mathbf{C}_{\mathbf{1 0}}\right)$ & 26,900 & 1.21 & Not observed \\
Lauryl $\left(\mathbf{C}_{\mathbf{1 2}}\right)$ & 33,650 & 1.24 & -33.9 \\
Myristyl $\left(\mathbf{C}_{\mathbf{1 4}}\right)$ & 32,00 & 1.25 & -2.5 \\
Palmityl $\left(\mathbf{C}_{\mathbf{1 6}}\right)$ & 35,600 & 1.36 & 19.3 \\
Stearyl $\left(\mathbf{C}_{\mathbf{1 8}}\right)$ & 40,000 & 2.22 & 47.3 \\
\hline
\end{tabular}

\section{b) Block copolymers based on monomers from FA}

Thereby, the numerous works about the ATRP optimization of FA-based (meth)acrylate monomers revealed the increasing interest toward the resulting polymers with well-defined structures. Indeed, linear poly(alkyl (meth)acrylate)s containing side chains longer or equal to $12 \mathrm{C}$-atom are able to crystallize and exhibit low glass transition temperature (Tg). ${ }^{120}$ Thus, long hydrophobic side chain monomers are interesting comonomers to afford innovative copolymers with well-defined structures and promising properties, which can be tunable according to the nature of the chosen FA-based monomer. For instance, Qin et al. reported well-defined triblock copolymers containing octadecylmethacrylate as nonpolar part and $t$ butyl methacrylate as polar part. ${ }^{112}$ Uniform phase separations were observed in ultra-thin films due to the difference of Tg between the middle block and the center block (Figure 4).

\section{(B)}
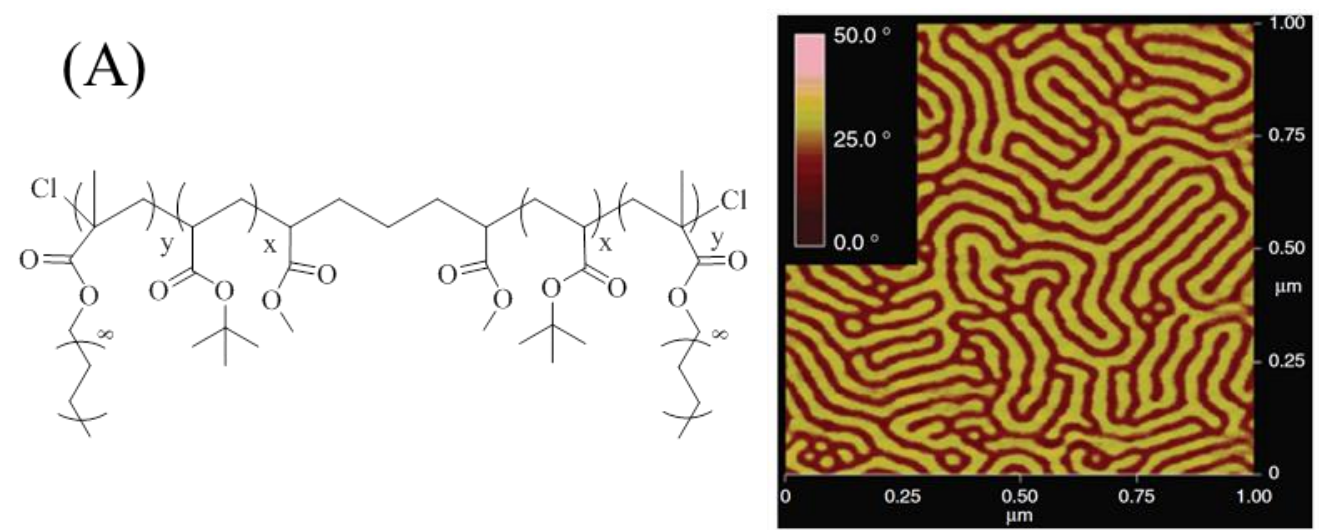

Figure 4: (A) Structure of tri-block copolymer PSMA-b-PtBA-b-PSMA prepared by ATRP and (B) tapping mode atomic force microscopy image of the triblock copolymer thin film ${ }^{112}$

Recently, Chatterjee et al. investigated a facile process for ATRP of high alkyl methacrylates, e.g., LMA at ambient temperature for the synthesis of triblock copolymers containing poly(methyl methacrylate)- $b$-poly(lauryl methacrylate)- $b$-poly(methyl methacrylate). ${ }^{118}$ More recently, Dutertre et al. synthesized, for the first time, diblock 
copolymers derived from lauryl and stearyl acrylates (PLA- $b$-PSA) through ATRP with welldefined structure. ${ }^{120}$ In their study, PLA- $b$-PSA have shown the crystallization of side-chains and phase segregation in the solid state. In another work, Holder et al. have successfully prepared the first well-defined amphiphilic copolymers containing lauryl acrylate and oligo(ethylene glycol) methyl ether methacrylate (PSA- $b$-POEGMA) that are susceptible to be thermally-responsive and give metal complex formation. ${ }^{117}$ One of the copolymer was shown to self-assemble as micelles in a dilute aqueous solution (Figure 5).

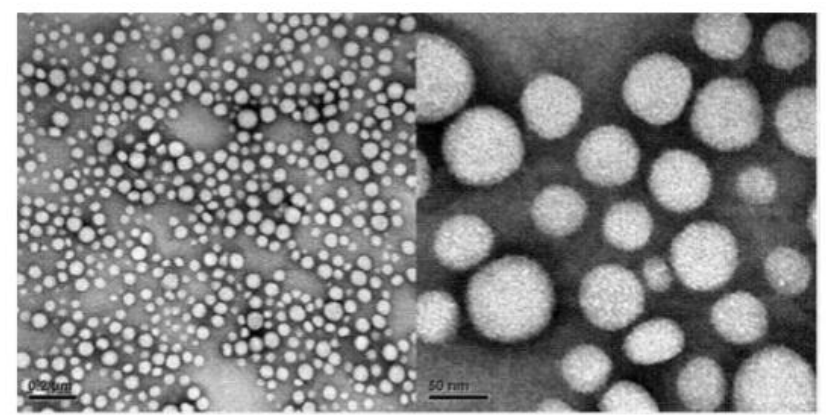

Figure 5: Transmission electron microscopy images of PSA-b-POEGMA block copolymer micelles ${ }^{117}$

Besides linear block copolymers, polymers with brush structures have also been prepared. Xu et al. reported the catalyzed ATRP polymerization of lauryl methacrylate using 2-(2-bromoisobutyryloxy)ethyl methacrylate (PBIEM) as poly-initiator to prepare welldefined cylindrical brush polymers with low dispersity $(<1.3)$ (Scheme 10). ${ }^{121}$ Because of the long alkyl side chains, these cylindrical copolymers are expected to have a good solubility in apolar solvents such as paraffin oil.
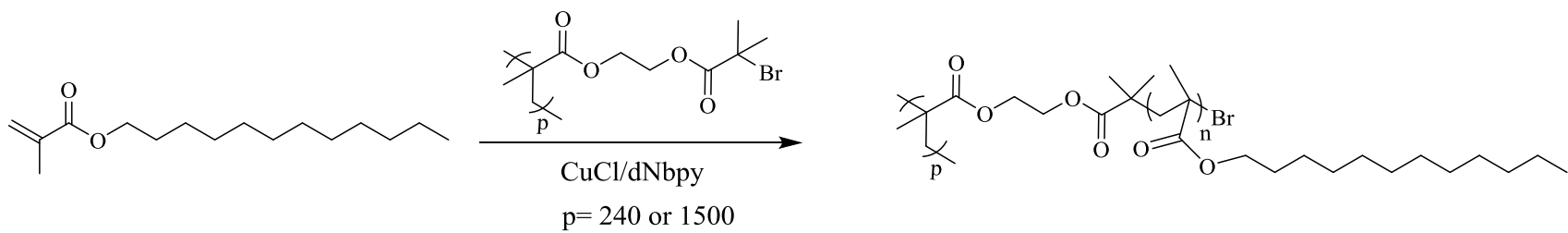

Scheme 10: ATRP polymerization of lauryl methacrylate with PBIEM as initiator

However, even if the ATRP process have led to various copolymers with innovative structures and promising properties, this process of polymerization has not been much expanded to other monomers from FA than common lauryl or stearyl (meth)acrylate. Considering the various other monomer examples mentioned in the first part of this review, there are still plenty of highly potential and innovative structures based on FA to develop 
through ATRP. However, even if ATRP allows a good control over chain growth, the presence of transition metal contaminants often requires additional purification steps.

\subsubsection{Reversible addition-fragmentation chain-transfer polymerization (RAFT)}

In the recent years, RAFT polymerization has emerged as an effective and alternative strategy to ATRP for producing living free radical polymerization with good control for a wide range of monomers without the contamination of transition metals. ${ }^{122}$ As far as we know, Zhu et al. were the first to report the successful RAFT polymerization of stearyl acrylate in benzene at $80{ }^{\circ} \mathrm{C}$ by using AIBN as thermal initiator and 2-cyanoprop-2-yl dithiobenzoate as suitable RAFT agent. ${ }^{123}$ After $14 \mathrm{~h}$ of reaction, the resulting poly(stearyl acrylate) was achieved in high conversion (80 \%) with targeted number average molecular weight $(48 \mathrm{~kg} / \mathrm{mol})$ and low dispersity $(<1.3)$. Since this study, RAFT polymerization with various experimental conditions has been mainly applied to monomers containing FA side chains including most often lauryl or stearyl (meth)acrylate. ${ }^{124-127}$ For instance, numerous non-polar solvents such as toluene, ${ }^{128}$ dioxane, ${ }^{129} n$-dodecane, $n$-heptane, $n$-dodecane, or isohexadecane $^{125}$ have been used to properly dissolved FA-based monomers for the preparation of well-defined (co)polymers. Generally, RAFT proceeds at a lower rate compared with conventional FRP, and consequently experiments are mostly carried out at a high monomer concentration or in bulk. ${ }^{130}$ For instance, Krivorotova et al. reported the bulk RAFT polymerization of lauryl acrylate and demonstrated a higher rate of polymerization than in dioxane without Trommsdorff effect. ${ }^{130}$ In bulk, $90 \%$ of FA-based methacrylate conversion was achieved after $2 \mathrm{~h}$ while only $70 \%$ of monomer conversion was attained in 6 $\mathrm{h}$ in solution. Well-defined structures were obtained for both processes in accordance to targeted molecular weights and narrow dispersity $(<1.08)$. Additionally, different suitable RAFT agents for long alkyl (meth)acrylate monomers including mainly cyano-methyl dodecyltrithiocarbonate, ${ }^{124}$ 2-cyanoprop-2-yl dithiobenzoate ${ }^{123}, \quad S$-methoxycarbonylphenylmethyl dithiobenzoate and 4-cyano-4-(phenylcarbonothioylthio)pentanoic acid ${ }^{129}$ have been also used for the preparation of various well-defined FA polymers (Figure 6). 
(A)
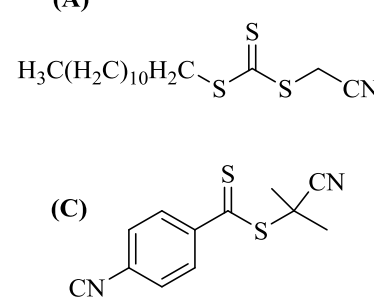

(B) $\mathrm{CN}$<smiles>C=C(SCCC(=O)O)SC(C)(C)CCCCCCCC</smiles>

(D)

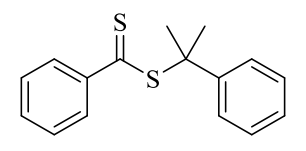

Figure 6: RAFT agents suitable for FA-based monomers: (A) cyano-methyl dodecyltrithiocarbonate (B) 4-cyano-4-(phenylcarbonothioylthio)pentanoic acid (C) 2-cyanoprop-2-yl dithiobenzoate (D) $S$ methoxycarbonylphenylmethyl dithiobenzoate

Thus, FA-based polymers have been used many times as macro RAFT agent (macroCTA) in RAFT polymerization and have offered a large variety of macromolecular structures. For instance, FA-based (meth)acrylate monomers have been copolymerized with various hydrophobic comonomers such as benzy (meth)acrylate, ${ }^{131,132}$ butyl methacrylate, ${ }^{133}$ methyl acrylate, ${ }^{134}$ and also with hydrophilic monomers such as poly(ethylene oxide) methacrylate, ${ }^{129}$ poly(ethylene oxide) monomethyl ether methacrylate, ${ }^{135}$ 2-hydroxyl methacrylate $^{136}$ for designing statistical, di or triblock copolymers with modulable or amphiphilic properties. ${ }^{125,134,137,138}$

Additionally, considering the high hydrophobicity of FA-based monomers, several papers focused on the RAFT dispersion of highly polar monomers in non-polar solvents by using polymers with FA side chains as macro chain transfer agents. ${ }^{88,126}$ For instance, Pei et $a l$. used the stearyl methacrylate as macroCTA (PSMA) with 3-phenylpropyl methacrylate (PPMA) to yield various block copolymers for the direct in situ preparation of self-assembled polymeric species. $^{139}$ Indeed, at 20 wt $\%$ total solids with a PSMA 19 macro-CTA, nanoparticles with spherical, worm, and vesicular morphologies were easily achieved by increasing the average degree of polymerization of the PPPMA block (Scheme 11). 


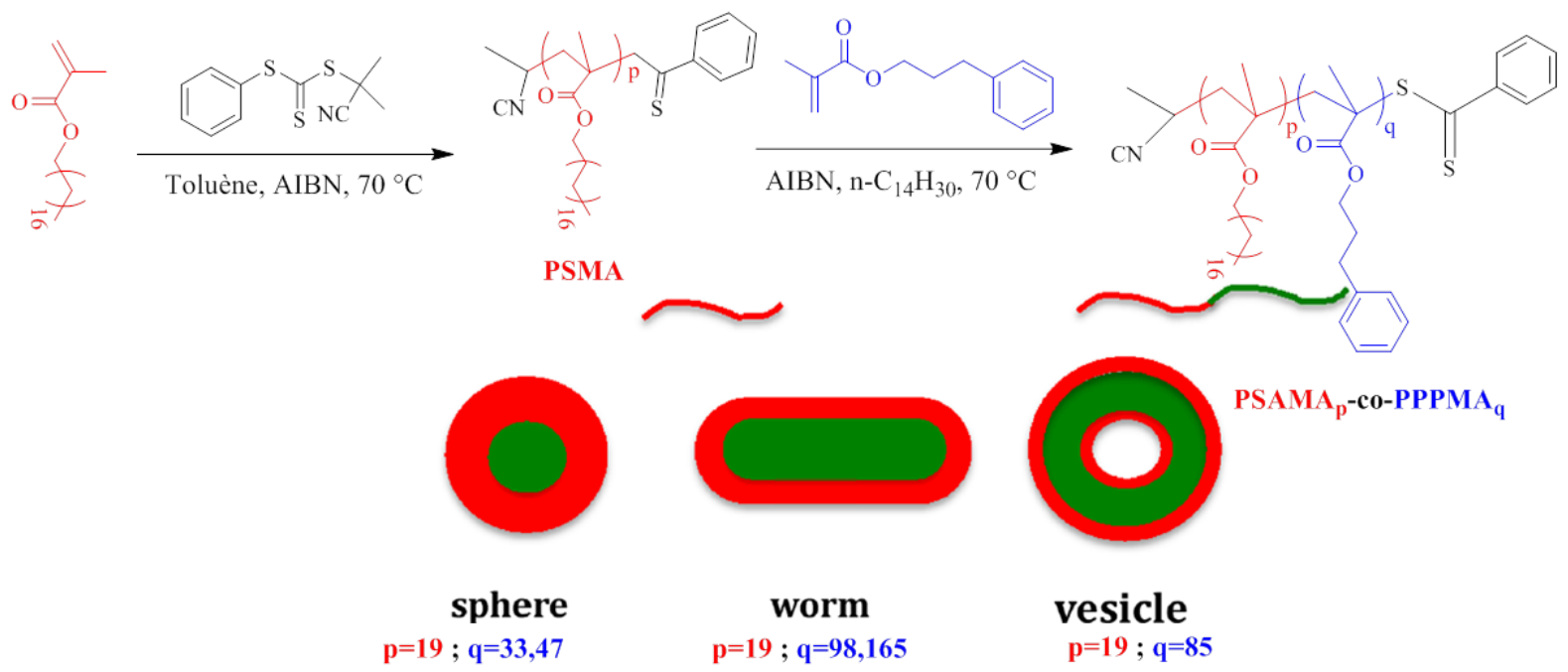

Scheme 11: Synthesis of PSMAp-co-PPPMA $q$ copolymer nanoparticles via RAFT dispersion in ntetradecane at $70{ }^{\circ} \mathrm{C}$

However, in most of the cases, RAFT polymerization has only been used for the same (meth)acrylate monomers including mainly lauryl or stearyl (meth)acrylate due to the ability of their respective polymers to crystallize despite the atacticity of the main chains. ${ }^{134}$ Thereby, Maiti et al. have recently studied the RAFT polymerization of innovative methacrylate monomer structures resulting from the direct esterification of FA containing different alkyl side chains from $\mathrm{C}_{8}$ to $\mathrm{C}_{18}$ with 2-hydroxy(ethyl) methacrylate (Scheme 12). ${ }^{70}$
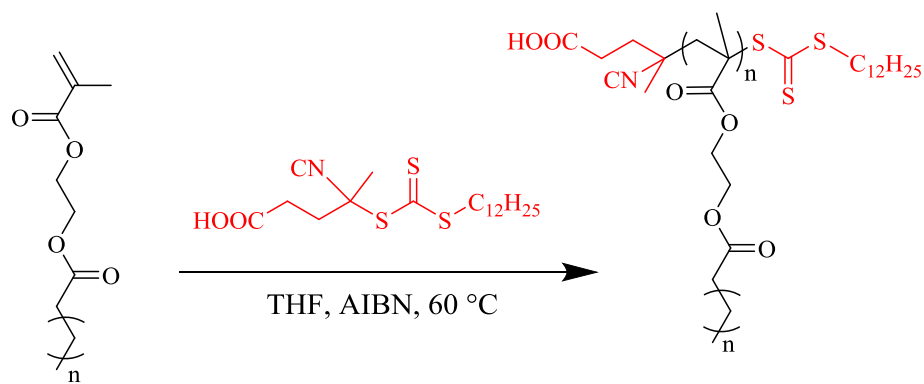

Scheme 12: Synthesis of side-chain fatty acid containing methacrylate RAFT polymerization

The RAFT polymerization of this series of innovative FA-based methacrylate monomers was performed in THF at $60{ }^{\circ} \mathrm{C}$ by using AIBN and and 4-cyano-4(dodecylsulfanylthiocarbony) sulfanypentanoic acid (CDP) as RAFT agent (CTA). ${ }^{70}$ High monomer conversions were achieved (up to $82 \%$ ) after $7 \mathrm{~h}$ of reaction and the resulting FAbased homopolymers (PFAMA) showed well-defined architectures with targeted molecular weights (ranging from 10 to $18 \mathrm{~kg} / \mathrm{mol})$ and narrow molecular weight distribution $(<1.19)$. As conventional poly(alkyl (meth)acrylate) containing, at least 12 carbons, ${ }^{119}$ saturated PFAMA developed by Maiti et al. displayed crystalline behavior depending on the chain 
length. The melting point of PFAMA increased from 12 to $47^{\circ} \mathrm{C}$ by increasing the number of carbons of their aliphatic chains from 14 to 18 .

Considering the potential of highly hydrophobic monomers with crystallinity, Maiti et al. firstly explored the preparation of well-defined amphiphilic block copolymers by using PFAMA as macroCTA and a polar comonomer, 2-(2-methoxyethoxy)ethyl methacrylate. ${ }^{70}$ This study only focused on the synthesis and confirmed the effectiveness of PFAMAS as suitable macroCTA to afford amphiphilic copolymers with well-defined structures. In further works, Maiti et al. have reported the RAFT synthesis of well-defined amphiphilic random copolymers based on their previous reported 2-(methacryloyloxy)ethyl stearate monomer (SAMA) and poly(ethylene glycol) methyl ether methacrylate (PEGMA) (Scheme 13). ${ }^{140}$ Even if both monomers are methacrylate derivatives, the study revealed that PEGMA is almost two times more reactive toward copolymerization than SAMA inducing a mixture of random copolymer enriched with PEGMA units. This observation was related to the bulkiness of SAMA compared to PEGMA. In the meantime, the resulting copolymers showed promising modulable crystallinity and solubility by simply varying the hydrophobic/hydrophilic ratio in the structure. Copolymers containing less than $30 \%$ of SAMA units were able to self-assemble into micellar type structure in water with critical micelle concentration values ranging from 4.6 to $2.3 \mathrm{mg} / \mathrm{L}$ while copolymers with SAMA content superior to $30 \%$ were able to show crystallinity (Figure 7).
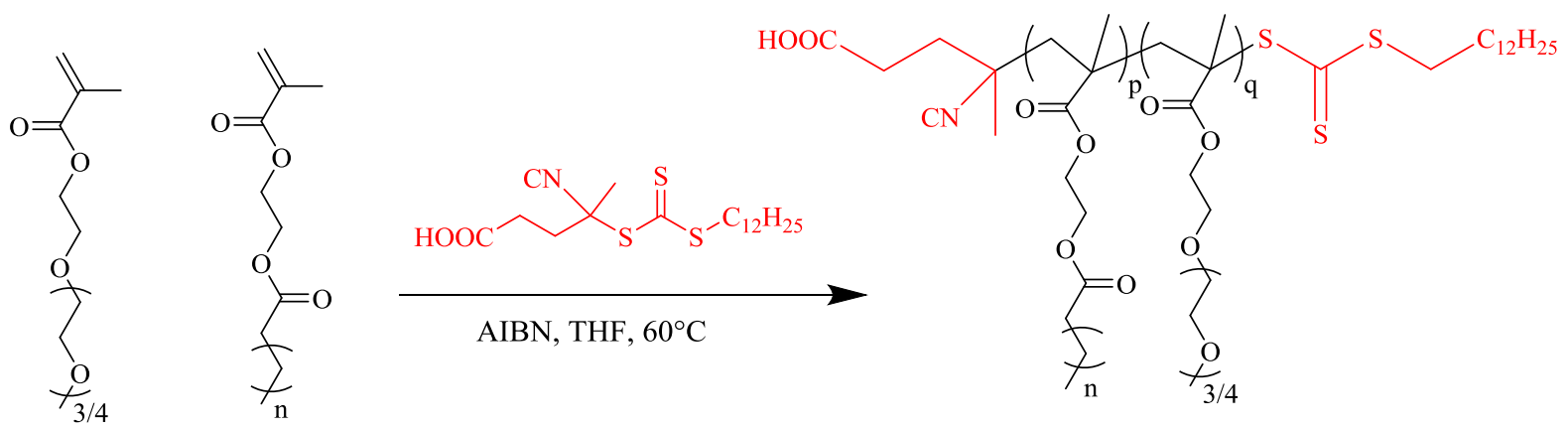

Scheme 13: Synthesis of P(SAMA-co-PEGMA) by RAFT polymerization 
(A)

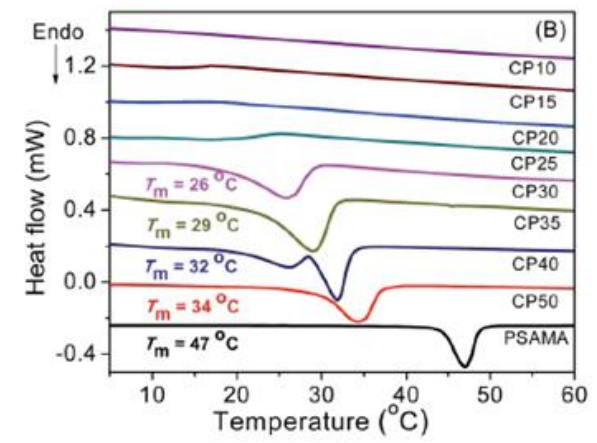

(B)

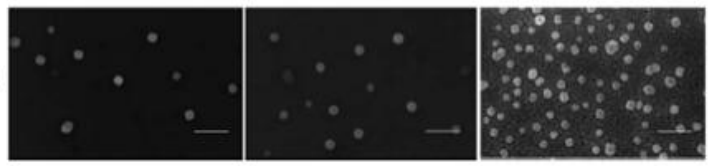

Figure 7: (A) DSC curves of various homo- and copolymers (CP-\%PEGMA) (B) Scanning electron microscopy images of CP10, CP20 and CP30 (from left to right). The scale bar corresponds to 200 $\mathrm{nm}$. Copolymer solutions in de-ionized water $\left(0.2 \mathrm{mg} \mathrm{mL}^{-1}\right)$ were deposited onto silicon wafer.

Maiti et al. extended this work by using a FA-based macroCTA based on 2(methacryloyloxy)ethyl oleate (MAEO) to prepare well-defined block copolymers with methyl methacrylate and PEGMA. ${ }^{69}$ The interesting property of the block containing poly(methacryloyloxyethyl oleate) (PMAEO) is the available internal unsaturation. This latter has been used to perform epoxidation or thiol-ene reactions on the PMAEO homopolymer (Scheme 14). Therefore, oleate pendant side-chains are ideal to introduce new functionalities through post-polymerization functionalizations and can easily allow the preparation of innovative architectures of FA-based copolymers. Taking this advantage, Maiti et al. have recently prepared a library of functional polymers derived from FA through postpolymerization reactions. ${ }^{141}$ 


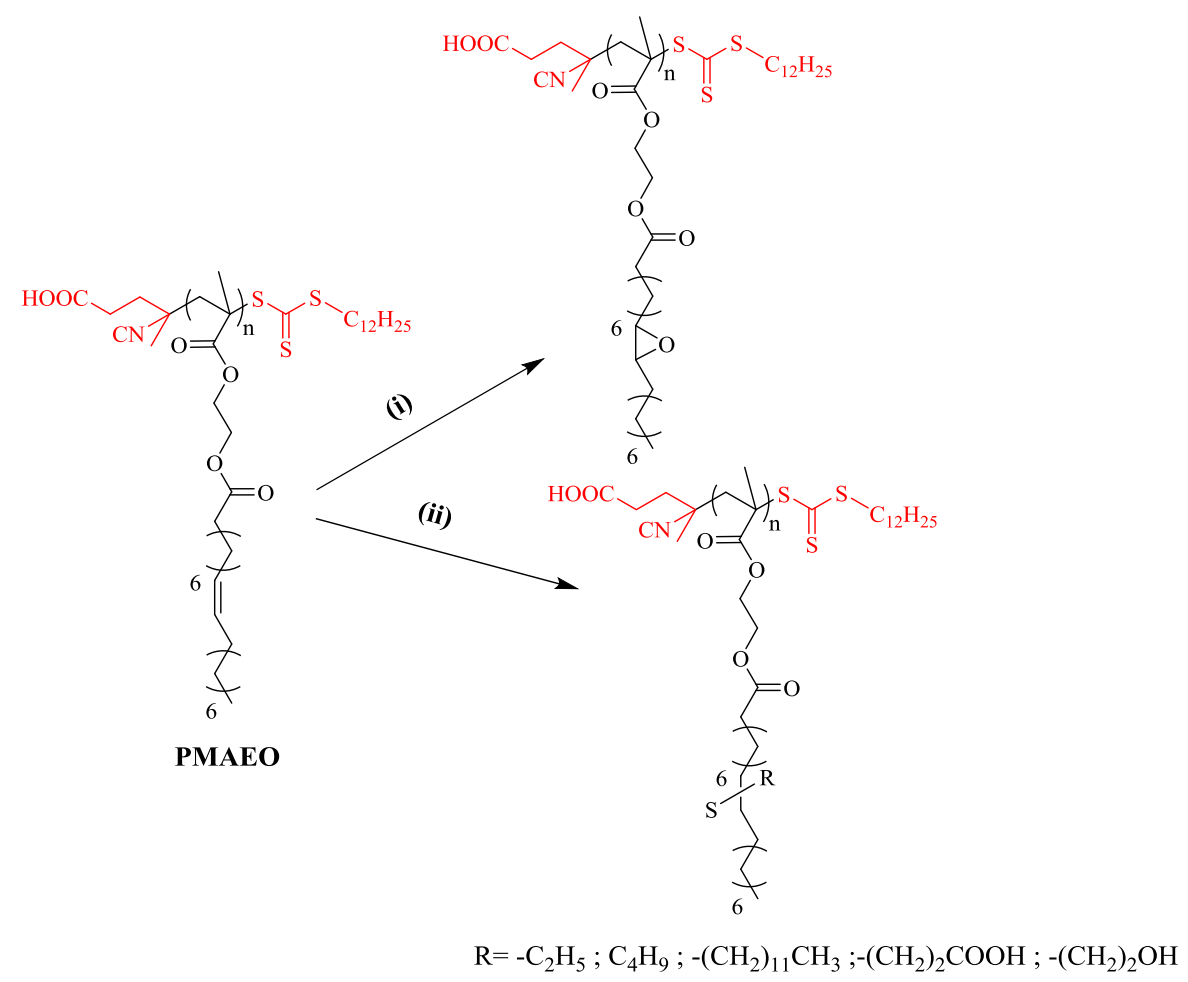

Scheme 14: Post-polymerization functionalizations of the double bonds in the resulting RAFT PMAEO polymer via (i) epoxidation using meta-chloroperbenzoic acid in dichloromethane at room temperature and via (ii) thiol-ene using various thiol compounds with AIBN as initiator in THF $60{ }^{\circ} \mathrm{C}$.

Recently, Jena et al. focused on the self-assembled organization in selective organic solvents of double-hydrophobic block copolymers containing side-chain FA and amino acid block segments, namely, poly(2-(methacryloyloxy)ethyl stearate)-b-poly(tertbutyloxycarbonyl phenylalanine methacryloyloxyethyl ester) (PSAMA- $b$-P(Boc-PheHEMA)). ${ }^{142}$ Various block copolymers with fixed PSAMA block lengths and variable block lengths of $\mathrm{P}($ Boc-Phe-HEMA) were synthesized with targeted molecular weights ranging from 6 to $35 \mathrm{~kg} / \mathrm{mol}$ and narrow dispersity (> 1.32). Considering the different solubility profiles of the two blocks, the resulting copolymers have shown remarkable self-assembly behavior in DMF, DMSO and acetonitrile but were insoluble in methanol or water. The deprotection of $\mathrm{P}$ (Boc-Phe-HEMA) block by using trifluoroacetic acid allowed the complete dissolution of the copolymers in methanol and water as well as self-assembled aggregation. The study revealed that the increase of $\mathrm{P}\left(\mathrm{H}_{3} \mathrm{~N}^{+}\right.$-Phe-HEMA) block had an influence on the morphological transition of self-assembled aggregates from spherical micelle to square- to rod-type in methanol. Figure 8 summarized the aggregate formation from the self-assembly of the studied block copolymers. 


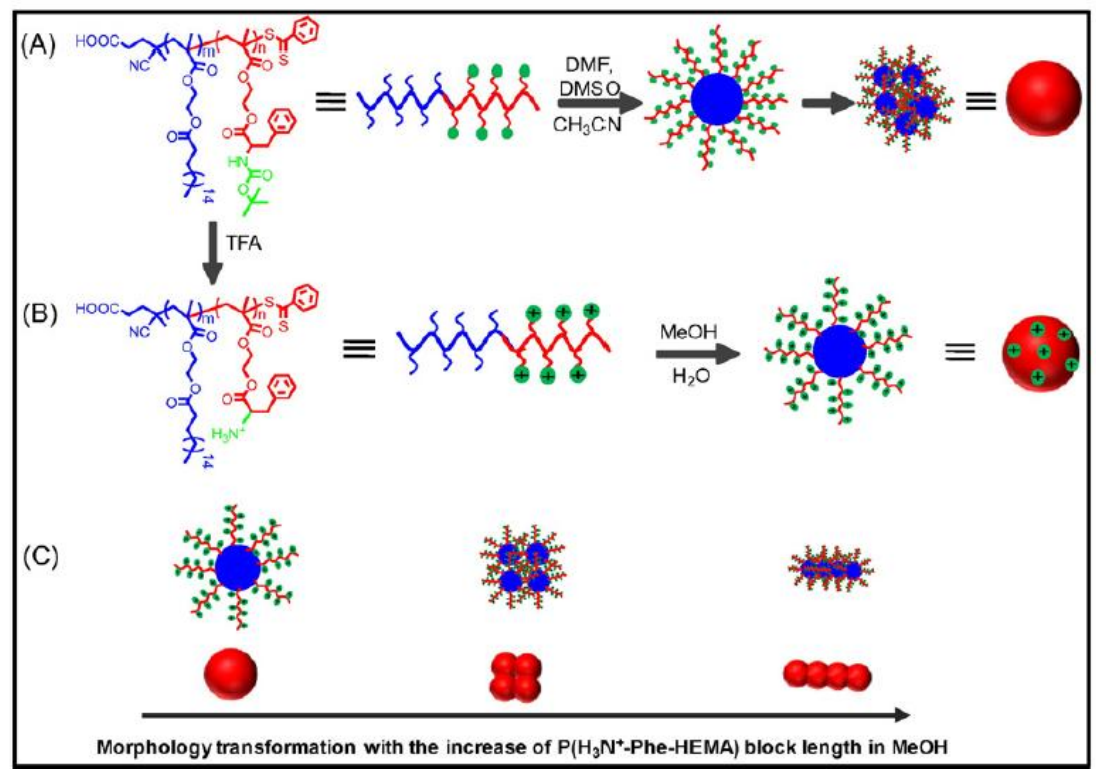

Figure 8: Illustration of the aggregate formation from the self-assembly of (A) PSAMA- $b$-P(Boc-PheHEMA) in DMF, DMSO and acetonitrile, (B) PSAMA- $b-\mathrm{P}\left(\mathrm{H}_{3} \mathrm{~N}^{+}\right.$-Phe-HEMA), (C) the morphological transition of self-assembled aggregates with the increase of PSAMA- $b-\mathrm{P}\left(\mathrm{H}_{3} \mathrm{~N}^{+}\right.$-Phe-HEMA) block length

Hence, FA containing monomers represent promising renewable resources and can offer a wide range of innovative architectures for (co)polymers obtained by RAFT polymerization. However, even if RAFT polymerization includes a good versatility toward the monomer choice and can be applied with various experimental conditions (solvent, temperature), this process suffers also from some drawbacks. For instance, in order to keep a good control over polymerization, moderate monomer conversion is required in order to avoid termination which always induces some wasted monomers. Additionally, a particular RAFT agent is generally suitable for a limited range of monomers. RAFT agents are not largely commercially available and are expensive. ${ }^{143}$ Moreover, the synthesis of RAFT agents typically requires a multi-step synthetic procedure as well as several purification steps. ${ }^{144}$ Finally, RAFT agents can be unstable over long time periods, are highly colored and can have a pungent odor related to the presence of sulfur compounds resulting from the decomposition of the dithioester moiety. ${ }^{145}$ Thereby, the presence of sulfur and color in the resulting (co)polymer may be undesirable for several applications and may require further chemical and physical purification steps to avoid them.

\subsection{Conclusion}

In summary, a wide range of polymers containing FA-based monomers or derivatives have been investigated in the literature using various radical polymerization techniques such 
as free radical polymerization (FRP) or controlled radical polymerization (CRP) with various experimental conditions (bulk, solution, (mini)emulsion...). Among all these methods, FRP appears as the simplest and the most widely used to provide easily biobased FA polymers. Nevertheless, techniques that are more promising, have recently emerged such as CRP techniques that allow the synthesis of well-defined FA-based (co)polymer with innovative architectures through ATRP and RAFT polymerizations which cannot be achieved via FRP. Thus, these several choices of radical processes gave the opportunity to obtain a variety of (co)polymers with a broad range of properties. The resulting (co)polymers may be of considerable interest for various applications, which are going to be discussed in the next section.

\section{Promising applications of FA-based (co)polymers}

Since the last few years, ecofriendly polymers resulting from the polymerization of FAbased monomers have known a wide expansion in various industrial applications. The high versatility of the FA-based monomer structures and the various available processes of radical polymerization offer a broad range of properties which explains their rapid increasing widespread. The purpose of the following part is not to report all FA-based polymer applications but to give an overview of the numerous fields where they present high potential.

\subsection{Waterborne coatings}

Since FA-based monomers have been involved in (mini)emulsion polymerization, they have recently appeared as a promising alternative to afford eco-friendly waterborne polymers. ${ }^{146}$ Recently, Barbosa et al. have shown that FA derivatives could be used as efficient coalescing agents to replace volatile organic compounds (VOC)s such as glycol ether or alcohols. ${ }^{67,68,93}$ In their work, an allylic FA derivative (AFAD) and an acrylic FA derivative (AcFA) were incorporated at $5 \mathrm{wt}$ \% in a reference resin containing methyl methacrylate and butyl methacrylate (50:50 wt.). The minimum film-forming temperatures of the new FAbased coatings were slightly lower than the reference $\left(-4^{\circ} \mathrm{C}\right.$ vs $-2^{\circ} \mathrm{C}$ for the reference $){ }^{92}$ This observation is related to the presence of long aliphatic chains in FA-polymers which induced high segment mobility through increased intermolecular distance. ${ }^{147}$ In addition, as FA-based polymers are non-volatile and remain after film formation, they can also undergo crosslinking through their internal available unsaturations, which has reduced the drying times (less than 50 minutes against 107 minutes for the reference) and improved the resulting film mechanical properties. However, a higher degree of crosslinking was observed for AcFA (60\%) 
compared to AFAD (48\%). ${ }^{92}$ This difference was related to the lower reactivity of the allylic groups compared to the acrylic ones. Thus, the copolymerization of AFAD has also occurred on the aliphatic double bonds, decreasing the number of reactive sites for oxidative curing during air drying. In the recent works of Moreno et al., successful examples of the incorporation of fully FA-based polymers have been used as binders in waterborne coatings. ${ }^{81,82,102}$ For instance, the potential performance as binders of polymer latexes resulting from $\mathrm{MOA}^{81}$ and $\mathrm{MLA}^{82}$ as well as their copolymers synthesized with the biobased $\alpha$-MBL have been investigated. ${ }^{99,100}$ As previously reported by Barbosa et al., the resulting FA-based polymers derived from methacrylate monomers with internal unsaturations can easily undergo cross-linking and a film formation with good mechanical properties. For instance, the Tg values of MOA and MLA homo- and copolymers increased with the filmification process with an increase in polymer stiffness as showed by the enhancement of Young's modulus. Moreover, high-Tg polymers coming from $\alpha$-MBL afforded various polymer latexes with a broad range of glass transition temperatures (between 0 and $60{ }^{\circ} \mathrm{C}$ in function of MBL comonomer ratio) which revealed a high potential as binders for coatings and paints. ${ }^{100}$ In further works, Moreno et al. have directly incorporated the FA-derivative latexes as binders into paint formulations. ${ }^{99}$ These latter were able to mimic the properties of a commercial paint in terms of hardness, gloss, flow viscosity behavior and open time, even though the eco-friendly paints were formulated using standard formulations, without any additional effort to improve the resulting paint properties. Moreover, the resulted formed films showed very good appearance without cracking when the paints were applied onto glass panels (Figure 9). Considering these very promising results, FA-based polymer materials have recently appeared as excellent candidates for sustainable waterborne paints.

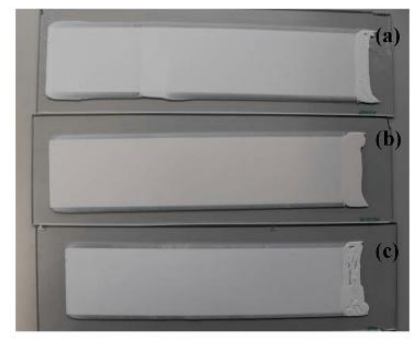

Figure 9: Films of waterborne paints (a) MOA-MMA; (b) commercial; (c) MLA-MMA

\subsection{Adhesives}


Lastly, FA-containing polymers have also shown promising properties for adhesive applications. ${ }^{9}$ For instance, in the study of Bunker et al., the polymer resulting from the radical polymerization of the acrylate methyl oleate (AMO) has shown considerable interest for pressure-sensitive adhesives (PSA) according to its physical properties. ${ }^{94}$ The AMO polymer showed a low $\mathrm{Tg}$ value of approximately $-40{ }^{\circ} \mathrm{C}$ comparing to $-52{ }^{\circ} \mathrm{C}$ for conventional PSA from n-butyl acrylate and $-70{ }^{\circ} \mathrm{C}$ for 2-ethyl acrylate. ${ }^{148}$ Indeed, a Tg less than room temperature is required for PSA applications in order to allow the polymer to quickly form an adhesive bond with the substrate. ${ }^{149}$ Additionally, it was shown that the peel energy in $180^{\circ}$ peel test of AMO polymer was similar to that required for a Post-it ${ }^{\mathrm{TM}}$ or an office tape. In another study, the same AMO monomer was copolymerized with methyl methacrylate (MMA,10 wt. \%) or with both MMA (10 wt. \%) and 1,4-butanediol diacrylate (BDDA, 5 wt. \%) to provide efficient biocompatible PSA. ${ }^{43}$ The resulting copolymers have shown higher tack than a commercial dispersion (Acronal ${ }^{\circledR} 220$ ) as well as a similar tack than a model dispersion containing ethylhexyl acrylate (2-EHA)-co-MMA which is also composed of branched long hydrophobic side chain like in FA monomers (Figure 10). Only the peel test value of the AMO-based polymer was slightly lower than commercial PSA.

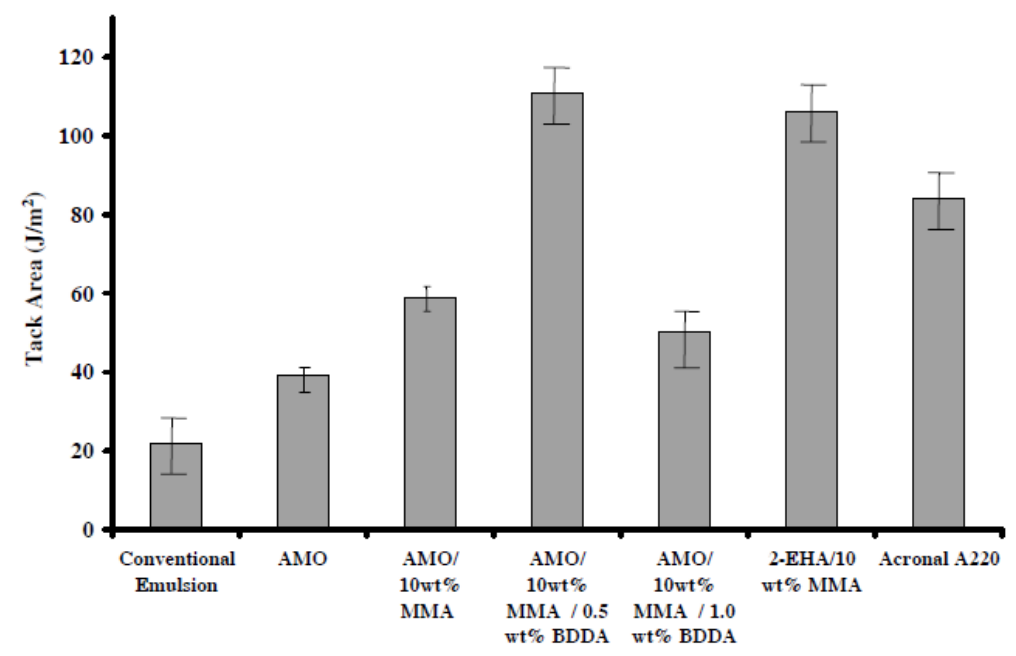

Figure 10: Tack of polymers to a polyethylene probe

More recently, Maaßen et al. investigated the homopolymerization of three polymers from oleate derivatives which showed typical characteristics of PSA. ${ }^{150}$ For instance, the resulting polymers exhibit a low elastic modulus, and a $\mathrm{Tg}$ value close to $-60{ }^{\circ} \mathrm{C}$ in accordance with the criterion of Dahlquist for PSA. ${ }^{150}$ Further improvements in PSA performances may be achieved by tuning various properties such as increasing polymer molecular weight or introducing an appropriate degree of weak cross-linking, long-chain branching or suitable comonomers. 


\subsection{Additives in lubricant application}

Polymers derived from (meth)acrylates containing long FA alkyl side chains have been also used as viscosity index improvers (VII) or flow improvers (also called pour point depressants or PPD) in lubricant applications to replace conventional petro-sourced (meth)acrylate additives (P(M)A). ${ }^{151-154}$ These "comb-like" polymers have the ability to decrease the viscosity-temperature dependency of lube oils through the coil expansion mechanism (Figure 11). ${ }^{155}$

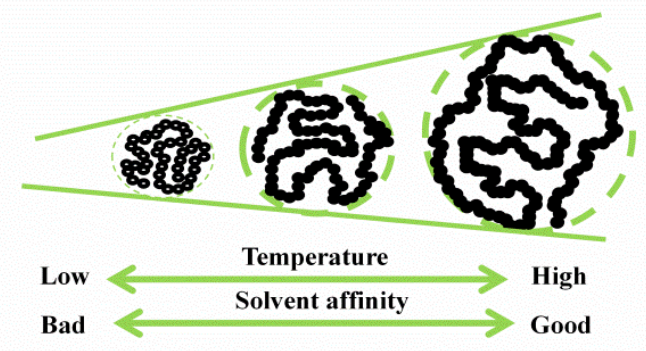

Figure 11: Coil expansion displayed by conventional petroleum (meth)acrylate additives

Moreover, these (meth)acrylate polymers are also known to decrease the rate of wax formation in lube oil which usually induces flow problems in pipelines. ${ }^{156}$ According to the literature, $\mathrm{P}(\mathrm{M})$ As have linear hydrophobic side chains which can interact with the long paraffin chains contained in the oil due to their similar structure while their polar ester part, dissimilar to the paraffin crystals, has the ability to block the extensive wax crystallization by creating steric hindrance between crystal agglomerates. ${ }^{157}$ For instance, Ghosh et al., who have worked a lot on this topic, reported the synthesis of poly(myristyl methacrylate) as potential additive for lube oils. ${ }^{90}$ Due to its ability to get expanded and thus being bettersolvated in lube oil with increasing temperature, the homopolymer has shown promising viscosity modifier properties. In the meantime, the same homopolymer revealed to be an efficient PPD because of its ability to interact with the paraffin content in lube oil inducing a delay in the oil crystallization process. Later, Jafari et al. have compared the efficiency of poly(dodecyl methacrylate) and poly(tetradodecyl methacrylate) as PPD in mineral lube oil. The results indicated that the higher is the chain length, the better is the efficiency of the polymer as PPD. ${ }^{158}$ This observation has been related to the higher ability of long alkyl chain to interact with oil paraffinic compounds. Soni et al. and Mohamad et al. confirmed this result by preparing efficient PPD-based copolymers containing FA-based methacrylates with various chain lengths. ${ }^{152,159}$ 
However, even if FA-based polymers appear as an interesting solution to replace current petroleum additives in lubricant application, only few studies have been focused on other FAbased monomer structures than those resulting from the conventional esterification of fatty alcohols with (meth)acrylate compounds. ${ }^{152}$ Recently, Kim et al. reported flow improverbased copolymers containing different ratios of styrene and 2-(methacryloyloxy)ethyl alkyl esters (HAMA) which resulted from the enzymatic trans-esterification of oleyl and lauryl methacrylates with HEMA (HOMA and HLMA respectively). All poly(styrene-co-alkyl methacrylate)s ( $\mathrm{PSt}_{\mathrm{n}} \mathrm{HAMA}$ with $\mathrm{m}=$ moles of styrene and $\mathrm{n}=$ moles of HLMA unit) copolymers have demonstrated a good ability in decreasing the initial pour point of an ultralow sulfur diesel and the best one, $\mathrm{PSt}_{2} \mathrm{HLMA}_{8}$, showed a $15 \pm 1.25{ }^{\circ} \mathrm{C}$ reduction in their pour points at 1,000 ppm concentration. However, even if such structures may also have demonstrated high efficiency as VII, the authors did not investigate this property. In this regard, Our team has used similar partially biobased polymer structures with different FA chain lengths and investigated their ability to get expanded with temperature in a mineral lube oil. ${ }^{160}$ The resulting methacrylate FA polymers have shown a higher polymer contribution in a mineral oil viscosity at high temperature than at low temperature which is characteristic of conventional petroleum VII. ${ }^{161}$ This observation was related to the FA polymers chain ability to get expanded with temperature and this specific coil expansion was improved by increasing the polymer molecular weight and the FA chain length. Thus, these last works showed the wide potential in using innovative FA-based monomer structures to prepare competitive polymeric additives through radical polymerization for lubricant applications.

\subsection{Thermoplastic elastomers}

Recent papers have focused on FA poly(meth)acrylates as sustainable sources to replace soft petro-sourced polydiene midblocks in the preparation of thermoplastic elastomers (TPE) owing to their various advantages. ${ }^{134,162}$ Firstly, the use of saturated FA poly(meth)acrylate as midblock allows to overcome the limited oxidative stability and UV resistance of usual polydienes related to the unsaturated midblocks. ${ }^{163,164}$ In addition, polymers resulting from FA derivatives display low glass transition temperature due to their long hydrophobic side chains and thus are suitable to provide a rubbery midblock in TPE triblock copolymer

structures. ${ }^{165,166}$ For instance, among the various poly(alkyl methacrylate)s, poly(lauryl methacrylate) (PLMA) has a low $\mathrm{T}_{\mathrm{g}}$ value of $-65{ }^{\circ} \mathrm{C}{ }^{167}$ which is comparable to those of poly(n-butyl acrylate) or poly(iso octyl acrylate) which have been also used as petro-sourced soft midblocks for TPE. Taking advantage of the low FA-based (meth)acrylate monomers, 
Wang et al. reported a promising triblock copolymer TPE containing lauryl acrylate-derived midblock (PLMA) and salicylic acid-derived end-blocks (PASEMA). The high incompatibility between PASEMA end-blocks with $\mathrm{T}_{\mathrm{g}}$ value close to $53{ }^{\circ} \mathrm{C}$ and PLMA midblock with low $\mathrm{T}_{\mathrm{g}}$ value $\left(-47^{\circ} \mathrm{C}\right)$ allowed a high degree of microphase separation between the rubbery and glassy phases which induced elastomeric behavior at room temperature. ${ }^{162}$ The same research group has also investigated the RAFT polymerization of stearyl and lauryl acrylates as the soft midblock with polystyrene as end-blocks to synthesize four series of poly(styrene- $b$-(lauryl acrylate-co-stearyl acrylate)- $b$-styrene) triblock copolymers. ${ }^{165}$ Their resulting properties were easily tuned by varying the composition of the acrylate midblock, including the melting temperature, the viscosity as well as the tensile properties without affecting the order-disorder transition temperature. More recently, another new generation of TPE materials based on graft copolymers was currently developed and exhibited improved mechanical properties related to those of conventional TPE. ${ }^{168}$ Some authors have worked on the preparation of such copolymers using methacrylate monomers containing FA side chains. For instance, Liu et al. synthesized by ATRP a graft copolymer entirely based on renewable feedstock including cellulose (Cell) as rigid backbone with dehydroabietic ethyl methacrylate (DAEMA) from rosin acid and lauric methacrylate (LMA) as rubbery side chains. ${ }^{138}$ The resulting graft copolymer, Cell-g-P(LMA-co-DAEMA), displayed excellent elastomeric properties, hydrophobicity as well as good thermal stability. However, it showed relatively poor mechanical properties, which limited the scope of their application. In further works, $\mathrm{Yu}$ et al. investigated sustainable TPEs with brush structures based on ethyl cellulose, lauryl methacrylate and furfural (EC-PMLA-THFMA) by the combination of ATRP and "click chemistry". ${ }^{169}$ The resulting multi-arm structures of these brush copolymers all exhibited the desired mechanical properties of TPEs (Figure 12). Considering their promising properties, these FA-materials containing both FA side chains and cellulose may be able to replace TPEs in various applications in the next decade. 


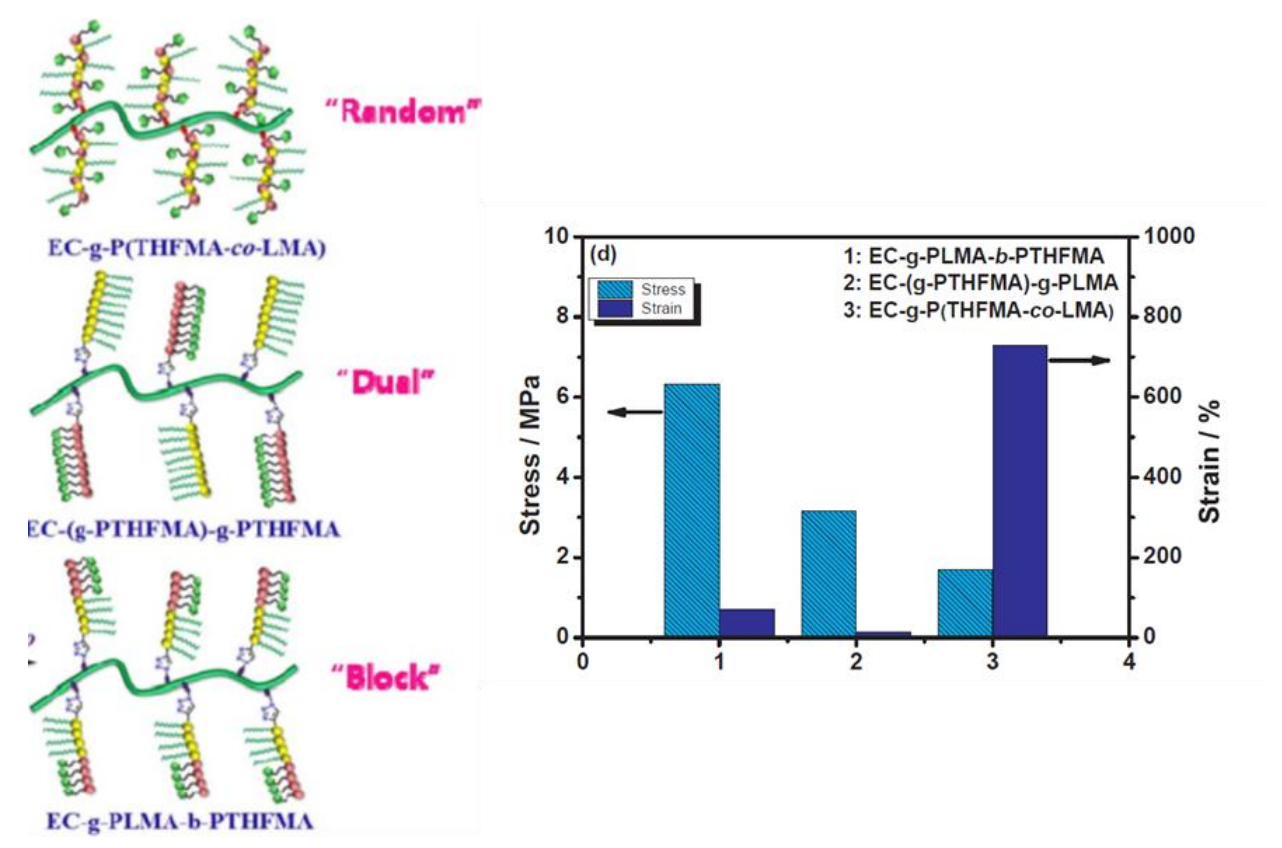

Figure 12: Structures and stress-strain curves for EC brush copolymers

\subsection{Biomedical applications}

FA-based polymers can be also extended to several biomedical applications thanks to their specific properties. Firstly, FAs can be easily metabolized in the human organism. Therefore, FA polymers are potentially biocompatible and may enhance the biodegradation of the material. In the meantime, the current progress in controlled radical polymerization of FAbased monomers has allowed the preparation of well-defined block copolymers which can self-assemble in specific solvents with a wide potential in drug delivery applications. ${ }^{132,170,171}$ For instance, Maiti et al. recently reported an easy strategy to prepare amphiphilic $\mathrm{pH}$ responsive capric acid-tryptophan block copolymers. ${ }^{172}$ The water solubility, stimuli responsive and self-assembly properties of the block copolymers were modulated by varying the block chain length of amino acid segment and fixing the DPn FA block segment. The resulting amphiphilic copolymers have been efficiently used to encapsulate and deliver doxorubicin as anticancer drug. Moreover, well-defined random amphiphilic copolymers containing stearic acid-based methacrylate and water soluble comonomers were recently reported by the same research group with modulable thermoresponsive properties by increasing the hydrophobic/hydrophilic ratio and demonstrated ability to self-assemble into micellar type structures in aqueous solution. ${ }^{140}$ The self-assembly in aqueous medium of random FA-based copolymers could become a topic of great interest for drug delivery application since they can be synthesized in a single polymerization step unlike usual block copolymers which are often synthesized in two steps. Moreover, the self-assembly of FA- 
based random copolymers can provide the means to the construction of tailored biobased materials with promising tunable properties. For instance, by simply adjusting the chain length of the FA contained in the copolymer, different crystallinity behaviors and hydrophobicities have been achieved by the same research group leading to copolymers with tunable properties. ${ }^{70}$ However, random copolymers are generally limited to spherical micelle structures although other types of higher order and more complex morphologies have been also achieved with block FA-based copolymers. ${ }^{131}$ For instance, Fielding et al. reported various thermoresponsive block copolymers containing lauryl methacrylate and benzyl methacrylate able to self-assemble in a variety of ordered nanostructures including spheres, worms and vesicles in n-dodecane (Figure 13, A).

(A)

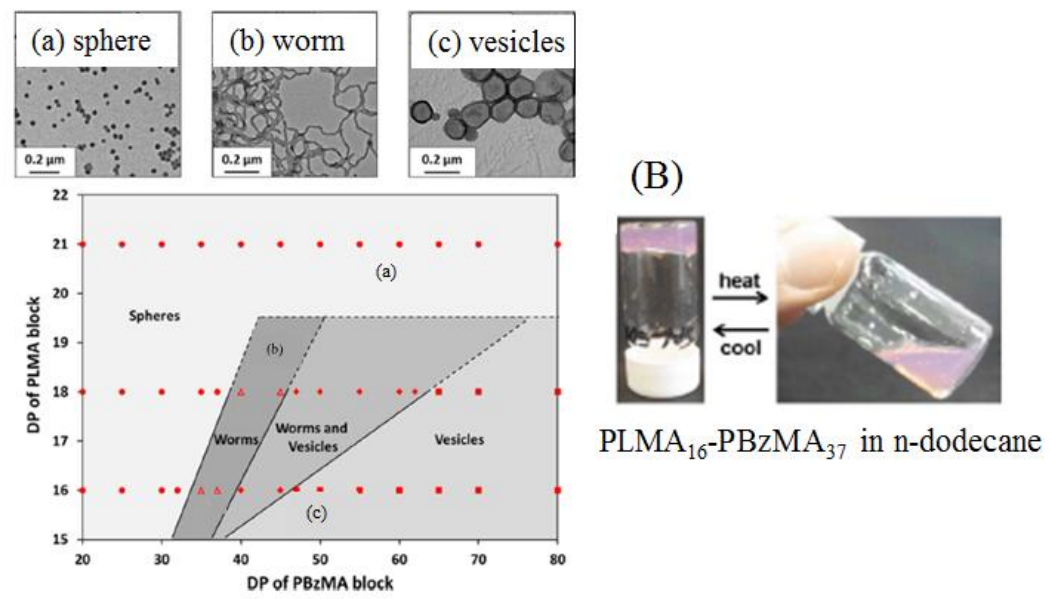

Figure 13: (A) Phase diagram constructed for PLMAx-PBzMAy diblock copolymer nanoparticles prepared by RAFT dispersion polymerization of BzMA in n-dodecane at 20\% w/w solids (B)Thermoresponsive solution behavior exhibited by $20 \%$ w/w PLMA16-PBzMA37 diblock copolymer nanoparticles in n-dodecane.

They have showed that the spherical and vesicular dispersions remain low viscosity fluids whereas the worms formed transparent free-standing physical gels at $20{ }^{\circ} \mathrm{C}$ (Figure 13, B). This thermal transition indicated a convenient loading mechanism for the in situ encapsulation of proteins or antibodies that suggested that such nano-objects may be useful in the field of intracellular delivery. Additionally, considering the growing demand of bioactive functional molecules in the field of biotechnology, Maiti et al. have extended the use FA-based copolymers in drug delivery by preparing nanoparticles derived from oleic acid with diversified features and functions through surface functionalizations. ${ }^{69,141}$ 


\section{CONCLUSION}

In the last few years, considerable efforts have been devoted to design and synthesize environmentally friendly materials able to mimic the properties of their petroleum-based counterpart. In this context, fatty acids (FA) recently appeared as promising candidates to develop novel monomers that can be viable alternatives to petroleum-derived raw materials. However, the main drawback of FA, is that the majority of them are not enough reactive to be involved directly in radical polymerization. Nevertheless, the growing demand for biobased polymers has encouraged the increasing interest in developing new synthetic routes to yield FA-based radically monomers, reactive in radical polymerization. The reactive sites of their backbone such as double bonds as well as carboxylic groups can offer a wide range of synthetic pathways for their functionalizations into sustainable monomers. Moreover, various processes of radical polymerization have been explored, including free radical polymerization and controlled radical polymerization (such as RAFT or ATRP), which can be performed on a wide range of FA-based monomers and more especially on (meth)acrylate monomers. However, for monomers containing also conjugated unsaturations, the reactivity can be limited by side reactions like chain transfer due to the presence of allylic hydrogen in the aliphatic chain.

Finally, (co)polymers derived from FA have proven their high efficiency in some applications including coatings, additives for lubricant, thermoplastic elastomers, or even in self-assembly for biomedical applications. The high hydrophobicity of the fatty chains could find developments in high value added materials like super-hydrophobic coatings but also in phase segregated materials for nanoscale patterns leading to wide variety of applications in the semiconductor industry. However, considering the high variety of FA through the world, the available pathways for functionalization FA into suitable monomers, as well as the versatility of radical polymerization processes, (co)polymers from FA may be also extended to others day-to-day applications in the next few years. 


\section{REFERENCES}

1. Hasnat, A. Modified Alkyd Resins as the Versatile Coating Materials derived from Vegetable Oils. Arch. Appl. Sci. Res.-Sch. Res. Libr. 9, 7-12 (2017).

2. Hintze-Brüning, H. Utilization of vegetable oils in coatings. Ind. Crops Prod. 1, 89-99 (1992).

3. Xu, X., Chen, L., Guo, J., Cao, X. \& Wang, S. Synthesis and characteristics of tung oilbased acrylated-alkyd resin modified by isobornyl acrylate. RSC Adv. 7, 30439-30445 (2017).

4. Chang, C.-W. \& Lu, K.-T. Linseed-oil-based waterborne UV/air dual-cured wood coatings. Prog. Org. Coat. 76, 1024-1031 (2013).

5. Adekunle, K. F. A Review of Vegetable Oil-Based Polymers: Synthesis and Applications. Open J. Polym. Chem. 05, 34-40 (2015).

6. Montero de Espinosa, L. \& Meier, M. A. R. Plant oils: The perfect renewable resource for polymer science?! Eur. Polym. J. 47, 837-852 (2011).

7. Gandini, A., Lacerda, T. M., Carvalho, A. J. F. \& Trovatti, E. Progress of Polymers from Renewable Resources: Furans, Vegetable Oils, and Polysaccharides. Chem. Rev. 116, 1637-1669 (2016).

8. Ronda, J. C., Lligadas, G., Galià, M. \& Cádiz, V. Vegetable oils as platform chemicals for polymer synthesis. Eur. J. Lipid Sci. Technol. 113, 46-58 (2011).

9. Lligadas, G., Ronda, J. C., Galià, M. \& Cádiz, V. Renewable polymeric materials from vegetable oils: a perspective. Mater. Today 16, 337-343 (2013).

10. Xia, Y. \& Larock, R. C. Vegetable oil-based polymeric materials: synthesis, properties, and applications. Green Chem. 12, 1893-1909 (2010).

11. Can, E., Wool, R. P. \& Küsefoğlu, S. Soybean and castor oil based monomers: Synthesis and copolymerization with styrene. J. Appl. Polym. Sci. 102, 2433-2447 (2006). 
12. Fernandez, A. M., Murphy, C. J., DeCosta, M. T., Manson, J. A. \& Sperling, L. H. Vernonia Oil Characterization and Polymerication, and Simultaneous Interpenetrating Polymer Networks Based on Vernonia Oil-Sebacic Acid/Polystyrene-DVB Compositions. in Polymer Applications of Renewable-Resource Materials 273-288 (Springer, Boston, MA, 1983). doi:10.1007/978-1-4613-3503-0_17

13. Maisonneuve, L., Chollet, G., Grau, E. \& Cramail, H. Vegetable oils: a source of polyols for polyurethane materials. OCL 23, D508 (2016).

14. Desroches, M., Caillol, S., Lapinte, V., Auvergne, R. \& Boutevin, B. Synthesis of Biobased Polyols by Thiol-Ene Coupling from Vegetable Oils. Macromolecules 44, 2489-2500 (2011).

15. Caillol, S. et al. Synthesis of new polyester polyols from epoxidized vegetable oils and biobased acids. Eur. J. Lipid Sci. Technol. 114, 1447-1459 (2012).

16. Gobin, M., Loulergue, P., Audic, J.-L. \& Lemiègre, L. Synthesis and characterisation of bio-based polyester materials from vegetable oil and short to long chain dicarboxylic acids. Ind. Crops Prod. 70, 213-220 (2015).

17. Lebarbé, T., Grau, E., Gadenne, B., Alfos, C. \& Cramail, H. Synthesis of Fatty AcidBased Polyesters and Their Blends with Poly(l-lactide) as a Way To Tailor PLLA Toughness. ACS Sustain. Chem. Eng. 3, 283-292 (2015).

18. Multi-functionalization of gallic acid. Synthesis of a novel bio-based epoxy resin. Eur. Polym. J. 49, 1185-1195 (2013).

19. Stemmelen, M. et al. A fully biobased epoxy resin from vegetable oils: From the synthesis of the precursors by thiol-ene reaction to the study of the final material. $J$. Polym. Sci. Part Polym. Chem. 49, 2434-2444 (2011).

20. Petrović, Z. S., Ionescu, M., Milić, J. \& Halladay, J. R. Soybean oil plasticizers as replacement of petroleum oil in rubber. Rubber Chem. Technol. 86, 233-249 (2013). 
21. Gaurav, A., Leite, M. L., Ng, F. T. T. \& Rempel, G. L. Transesterification of Triglyceride to Fatty Acid Alkyl Esters (Biodiesel): Comparison of Utility Requirements and Capital Costs between Reaction Separation and Catalytic Distillation Configurations. Energy Fuels 27, 6847-6857 (2013).

22. Sevim Z. Erhan. Lubricant basestocks from vegetable oils. Ind. Crops Prod. 11 279-282 (2000).

23. Somani, K. P., Kansara, S. S., Patel, N. K. \& Rakshit, A. K. Castor oil based polyurethane adhesives for wood-to-wood bonding. Int. J. Adhes. Adhes. 23, 269-275 (2003).

24. Samarth, N. B. \& Prakash, M. Modified Vegetable Oil Based Additives as a Future Polymeric Material. Open J. Org. Polym. Mater. 1-22 (2015).

25. Nesvadba, P. Radical Polymerization in Industry. in Encyclopedia of Radicals in Chemistry, Biology and Materials (eds. Chatgilialoglu, C. \& Studer, A.) (John Wiley \& Sons, Ltd, 2012). doi:10.1002/9781119953678.rad080

26. Matyjaszewski, K. \& Spanswick, J. Controlled/living radical polymerization. Mater. Today 8, 26-33 (2005).

27. Eisenlohr, K.-H., Voeste, T. \& Ag, M. Process for the production of fatty alcohols by catalytic hydrogenation of fatty acids and their derivatives. (1961).

28. Sánchez, M. A., Torres, G. C., Mazzieri, V. A. \& Pieck, C. L. Selective hydrogenation of fatty acids and methyl esters of fatty acids to obtain fatty alcohols-a review. J. Chem. Technol. Biotechnol. 92, 27-42 (2017).

29. Khalkar, S., Bhowmick, D. \& Pratap, A. Synthesis of polymers from fatty alcohol and acrylic acid and its impact on tribological properties. J. Oleo Sci. 62, 167-173 (2013).

30. Warwel, S., Steinke, G. \& Klaas, M. R. gen. An efficient method for lipase-catalysed preparation of acrylic and methacrylic acid esters. Biotechnol. Tech. 10, 283-286 (1996). 
31. Chen, F.-B. \& Bufkin, B. G. Crosslinkable emulsion polymers by autoxidation. I. Reactivity ratios. J. Appl. Polym. Sci. 30, 4571-4582 (1985).

32. Çayli, G. \& Meier, M. A. R. Polymers from renewable resources: Bulk ATRP of fatty alcohol-derived methacrylates. Eur. J. Lipid Sci. Technol. 110, 853-859 (2008).

33. Ahmed, M. R., Mohammed, A. H. A.-K. \& A.hamad, M. Synthesis, Characterization and Performance Evaluation of Poly Octadecyl Methacrylate and Poly Octadecyl Methacrylate-CoMethylmethacrylate as an Additive for Lubricating Oil. IOSR J. Appl. Chem. 10, 50-58 (2017).

34. Soldi, R. A., Oliveira, A. R. S., Barbosa, R. V. \& César-Oliveira, M. A. F. Polymethacrylates: Pour point depressants in diesel oil. Eur. Polym. J. 43, 3671-3678 (2007).

35. Pelletier, H., Belgacem, N. \& Gandini, A. Acrylated vegetable oils as photocrosslinkable materials. J. Appl. Polym. Sci. 99, 3218-3221 (2006).

36. Mousaa, I. M., Ibrahim, S. M. \& Radi, H. Coating Characteristics of UV Curable Epoxy Acrylate Oligomer Modified with Acrylated Sunflower Oil. Arab J. Nucl. Sci. Appl. 47, $1-13$ (2014).

37. Saithai, P. Effects of different epoxidation methods of soybean oil on the characteristics of acrylated epoxidized soybean oil-co-poly(methyl methacrylate) copolymer. Express Polym. Lett. 7, 910-924 (2013).

38. Campanella, A., La Scala, J. J. \& Wool, R. P. The use of acrylated fatty acid methyl esters as styrene replacements in triglyceride-based thermosetting polymers. Polym. Eng. Sci. 49, 2384-2392 (2009).

39. Medeiros, A. M. M. S., Machado, F., Rubim, J. C. \& McKenna, T. F. L. Bio-based copolymers obtained through miniemulsion copolymerization of methyl esters of acrylated fatty acids and styrene. J. Polym. Sci. Part Polym. Chem. 55, 1422-1432 (2017). 
40. Huang, Y.-B. et al. Influence of alkenyl structures on the epoxidation of unsaturated fatty acid methyl esters and vegetable oils. $R S C A d v$ 5, 74783-74789 (2015).

41. La Scala, J. J. Fatty Acid-Based Monomers as Styrene Replacements for Liquid Molding Resins. Polymer 45, 7729-7737 (2004).

42. Klapperich, C. M. et al. A novel biocompatible adhesive incorporating plant-derived monomers. J. Biomed. Mater. Res. A 91A, 378-384 (2009).

43. Bunker, S., Staller, C., Willenbacher, N. \& Wool, R. Miniemulsion polymerization of acrylated methyl oleate for pressure sensitive adhesives. Int. J. Adhes. Adhes. 23, 29-38 (2003).

44. Walther, S., Strehmel, N., Schlorholz, M., Strehmel, B. \& Strehmel, V. Photopolymerization of Functionalized Monomers Derived from Oleic Acid. $J$. Photopolym. Sci. Technol. 29, 123-132 (2016).

45. Eren, T. \& Küsefoğlu, S. H. One step hydroxybromination of fatty acid derivatives. Eur. J. Lipid Sci. Technol. 106, 27-34 (2004).

46. Eren, T. \& Küsefoğlu, S. H. Synthesis and polymerization of the bromoacrylated plant oil triglycerides to rigid, flame-retardant polymers. J. Appl. Polym. Sci. 91, 2700-2710 (2004).

47. Jovtscheff, A. Brom-Acetoxylierung einiger ungesättigter Fettsäuren. J. Für Prakt. Chem. 28, 186-198 (1965).

48. Ritter, J. J. \& Minieri, P. P. A New Reaction of Nitriles. I. Amides from Alkenes and Mononitriles1. J. Am. Chem. Soc. 70, 4045-4048 (1948).

49. Roe, E. T. \& Swern, D. Fatty Acid Amides. VI.2 Preparation of Substituted Amidostearic Acids by Addition of Nitriles to Oleic Acid3. J. Am. Chem. Soc. 75, 5479-5481 (1953). 
50. Blum, S., Gertler, S., Sarel, S. \& Sinnreich, D. Formation and mass spectral fragmentation of Ritter products from some monoenic fatty acids. Location of double-bond position in unsaturated acids. J. Org. Chem. 37, 3114-3120 (1972).

51. Eren, T. \& Kusefoglu, S. H. Synthesis and polymerization of the acrylamide derivatives of fatty compounds. J. Appl. Polym. Sci. 97, 2264-2272 (2005).

52. Murray, R. E. Transvinylation reaction. (1991).

53. Murray, R. E. Transvinylation process for the preparation of thermally labile vinyl compounds and vinyl compounds prepared from thermally labile acids. (1992).

54. Vallejos \& Christidis. Transvinylation of carboxylic acids. (1993).

55. Murray, R. E. \& Lincoln, D. M. New catalytic route to vinyl esters. Catal. Today 13, 93$102(1992)$.

56. Teeter, H. M. Vinyl monomers derived from fats and oils. J. Am. Oil Chem. Soc. 40, 143$156(1963)$.

57. Harrison, S. A. \& Wheeler, D. H. The Polymerization of Vinyl and Allyl Esters of Fatty Acids1a,b. J. Am. Chem. Soc. 73, 839-842 (1951).

58. Adelman, R. L. The interchange reaction of vinyl acetate with organic acids. J. Org. Chem. 14, 1057-1077 (1949).

59. M Macdonald, J. Transvinylation using mercuric acetate/perchloric acid catalyst. (1967).

60. Hopff, H. \& Osman, M. A. The vinyl interchange reaction. Tetrahedron 24, 2205-2214 (1968).

61. Waller, F. J. Catalytic transvinylation of vinyl esters. (1991).

62. Nakagawa, H., Okimoto, Y., Sakaguchi, S. \& Ishii, Y. Synthesis of enol and vinyl esters catalyzed by an iridium complex. Tetrahedron Lett. 44, 103-106 (2003).

63. Vilela, C., Rua, R., Silvestre, A. J. D. \& Gandini, A. Polymers and copolymers from fatty acid-based monomers. Ind. Crops Prod. 32, 97-104 (2010). 
64. Jebrane, M., Terziev, N. \& Heinmaa, I. The reactivity of linseed and soybean oil with different epoxidation degree towards vinyl acetate and impact of the resulting copolymer on the wood durability. Biomacromolecules 18, 498-504 (2017).

65. Chang, S.-P. \& Miwa, T. K. Allyl esters of crambe-derived long-chain fatty acids and their polymers. J. Appl. Polym. Sci. 24, 441-454 (1979).

66. Chow, R. C. L. \& Marvel, C. S. Copolymerization of allyl esters of some fatty acids. $J$. Polym. Sci. [A1] 6, 1515-1521 (1968).

67. Barbosa, J. V., Oliveira, F., Moniz, J., Magalhães, F. D. \& Bastos, M. M. S. M. Synthesis and Characterization of Allyl Fatty Acid Derivatives as Reactive Coalescing Agents for Latexes. J. Am. Oil Chem. Soc. 89, 2215-2226 (2012).

68. Barbosa, J. V., Veludo, E., Moniz, J., Magalhães, F. D. \& Bastos, M. M. S. M. Synthesis and characterization of acrylic fatty acid derivative and use as reactive coalescing agent. Eur. J. Lipid Sci. Technol. 114, 1175-1182 (2012).

69. Maiti, B., Kumar, S. \& De, P. Controlled RAFT synthesis of side-chain oleic acid containing polymers and their post-polymerization functionalization. $R S C A d v \mathbf{4}, 56415-$ 56423 (2014).

70. Maiti, B. \& De, P. RAFT polymerization of fatty acid containing monomers: controlled synthesis of polymers from renewable resources. RSC Adv. 3, 24983-24990 (2013).

71. Cho, H.-G., Park, S.-Y., Jegal, J., Song, B.-K. \& Kim, H.-J. Preparation and characterization of acrylic polymers based on a novel acrylic monomer produced from vegetable oil. J. Appl. Polym. Sci. 116, 736-742 (2010).

72. Kim, Y.-W., Eom, G. T., Hong, J.-S. \& Chung, K.-W. Fatty Acid Alkyl Esters as Feedstocks for the Enzymatic Synthesis of Alkyl Methacrylates and Polystyrene-co-alkyl Methacrylates for use as Cold Flow Improvers in Diesel Fuels. J. Am. Oil Chem. Soc. 88, $1727-1736$ (2011). 
73. Tarnavchyk, I., Popadyuk, A., Popadyuk, N. \& Voronov, A. Synthesis and Free Radical Copolymerization of a Vinyl Monomer from Soybean Oil. ACS Sustain. Chem. Eng. 3, $1618-1622$ (2015).

74. Demchuk, Z. et al. Free Radical Polymerization Behavior of the Vinyl Monomers from Plant Oil Triglycerides. ACS Sustain. Chem. Eng. 4, 6974-6980 (2016).

75. Yuan, L., Wang, Z., Trenor, N. M. \& Tang, C. Robust Amidation Transformation of Plant Oils into Fatty Derivatives for Sustainable Monomers and Polymers. Macromolecules 48, 1320-1328 (2015).

76. Yuan, L., Wang, Z., Trenor, N. M. \& Tang, C. Amidation of triglycerides by amino alcohols and their impact on plant oil-derived polymers. Polym Chem 7, 2790-2798 (2016).

77. Delatte, D. et al. Synthesis and characterization of a soybean oil-based macromonomer. $J$. Appl. Polym. Sci. 131, n/a-n/a (2014).

78. Can, E., La Scala, J. J., Sands, J. M. \& Palmese, G. R. The synthesis of 9-10 Dibromo stearic acid glycidyl methacrylate and its use in vinyl ester resins. J. Appl. Polym. Sci. 106, 3833-3842 (2007).

79. Dey, T. Properties of vinyl ester resins containing methacrylated fatty acid comonomer: the effect of fatty acid chain length. Polym. Int. 56, 853-859 (2007).

80. Li, S. H., Yang, X. J., Huang, K., Li, M. \& Xia, J. L. Preparation and Characterization of Dimer Fatty Acids-Based Vinyl Ester Resin Monomer. Adv. Mater. Res. 721, 86-89 (2013).

81. Moreno, M., Goikoetxea, M. \& Barandiaran, M. J. Biobased-waterborne homopolymers from oleic acid derivatives. J. Polym. Sci. Part Polym. Chem. 50, 4628-4637 (2012). 
82. Moreno, M., Miranda, J. I., Goikoetxea, M. \& Barandiaran, M. J. Sustainable polymer latexes based on linoleic acid for coatings applications. Prog. Org. Coat. 77, 1709-1714 (2014).

83. Matyjaszewsk, K. \& Davis, T. P. Handbook of Radical Polymerization. (2002).

84. Eren, T. \& Küsefoğlu, S. H. Synthesis and characterization of copolymers of bromoacrylated methyl oleate. J. Appl. Polym. Sci. 94, 2475-2488 (2004).

85. O’Shaughnessy, B. \& Yu, J. Autoacceleration in Free Radical Polymerization. 1. Conversion. Macromolecules 27, 5067-5078 (1994).

86. Patel, M. R., Chitte, P. S. \& Bharambe, D. P. Oleic acid based polymeric flow improvers for Langhnaj (North Gujarat, India) crude oil. Egypt. J. Pet. (2016). doi:10.1016/j.ejpe.2015.04.006

87. Xu, W., Zhu, X., Cheng, Z. \& Chen, J. Atom transfer radical polymerization of lauryl methacrylate. J. Appl. Polym. Sci. 90, 1117-1125 (2003).

88. Cunningham, V. J., Armes, S. P. \& Musa, O. M. Synthesis, characterisation and Pickering emulsifier performance of poly(stearyl methacrylate)-poly( $N$-2-(methacryloyloxy)ethyl pyrrolidone) diblock copolymer nano-objects via RAFT dispersion polymerisation in $n$ dodecane. Polym Chem 7, 1882-1891 (2016).

89. Mahabadi, H. K. \& O’Driscoll, K. F. Free radical polymerization kinetics of n-lauryl methacrylate. Makromol Chem 179, 1921-1928 (1978).

90. Ghosh, P. \& Karmakar, G. Synthesis and Characterization of Polymyristyl Acrylate as a Potential Additive for Lubricating Oil. Am. J. Polym. Sci. 2, 1-6 (2012).

91. Jukic, A. Viscosity and rheological properties of mineral lubricating oils containing dispersive polymethacrylate additives. Goriva Maziva 49, 239 (2010).

92. Barbosa, J. V. et al. Low VOC self-crosslinking waterborne acrylic coatings incorporating fatty acid derivatives. Prog. Org. Coat. 76, 1691-1696 (2013). 
93. Barbosa, J. V., Moniz, J., Mendes, A., Magalhães, F. D. \& Bastos, M. M. S. M. Incorporation of an acrylic fatty acid derivative as comonomer for oxidative cure in acrylic latex. J. Coat. Technol. Res. 11, 765-773 (2014).

94. Bunker, S. P. \& Wool, R. P. Synthesis and characterization of monomers and polymers for adhesives from methyl oleate. J. Polym. Sci. Part Polym. Chem. 40, 451-458 (2002).

95. Leyrer, R. J. \& Mächtle, W. Emulsion polymerization of hydrophobic monomers like stearyl acrylate with cyclodextrin as a phase transfer agent. Macromol. Chem. Phys. 201, $1235-1243$

96. Jensen, A. T., Sayer, C., Araújo, P. H. H. \& Machado, F. Emulsion copolymerization of styrene and acrylated methyl oleate: Emulsion copolymerization of styrene and acrylated methyl oleate. Eur. J. Lipid Sci. Technol. 116, 37-43 (2014).

97. Jensen, A. T., de Oliveira, A. C. C., Gonçalves, S. B., Gambetta, R. \& Machado, F. Evaluation of the emulsion copolymerization of vinyl pivalate and methacrylated methyl oleate. J. Appl. Polym. Sci. 133, (2016).

98. Schork, F. J. et al. Miniemulsion Polymerization. Polym. Part. 129-255 doi:10.1007/b100115

99. Moreno, M. et al. Eco-paints from bio-based fatty acid derivative latexes. Prog. Org. Coat. 81, 101-106 (2015).

100. Moreno, M., Goikoetxea, M., de la Cal, J. C. \& Barandiaran, M. J. From fatty acid and lactone biobased monomers toward fully renewable polymer latexes. J. Polym. Sci. Part Polym. Chem. n/a-n/a (2014). doi:10.1002/pola.27422

101. Moreno, M., Goikoetxea, M. \& Barandiaran, M. J. Surfactant-Free Miniemulsion Polymerization of a Bio-Based Oleic Acid Derivative Monomer: Surfactant-Free Miniemulsion Polymerization of a Bio-Based .... Macromol. React. Eng. 8, 434-441 (2014). 
102. Moreno, M., Goikoetxea, M. \& Barandiaran, M. J. Surfactant-Free Miniemulsion Polymerization of a Bio-Based Oleic Acid Derivative Monomer: Surfactant-Free Miniemulsion Polymerization of a Bio-Based .... Macromol. React. Eng. 8, 434-441 (2014).

103. Kaur, M. \& Srivastava, A. K. Photopolymerization: a review. J. Macromol. Sci. Part C 42, 481-512 (2002).

104. Müller, R. \& Wilke, G. Synthesis and radiation curing of acrylated castor oil glycerides. J. Coat. Technol. Res. 11, 873-882 (2014).

105. Habib, F. \& Bajpai, M. Synthesis and characterization of acrylated epoxidized soybean oil for UV cured coatings. (2011).

106. Liu, H., Lu, W. \& Liu, S. Development of acrylated soybean oil-based UV-curable coatings with high impact strength from low viscosity oligomer. J. Appl. Polym. Sci. 135, (2018).

107. Mhanna, A. et al. Photopolymerizable Synthons from Glycerol Derivatives. J. Am. Oil Chem. Soc. 91, 337-348 (2014).

108. Bigot, S. et al. Undecylenic acid: A tunable bio-based synthon for materials applications. Eur. Polym. J. 74, (2015).

109. Ganster, B., Fischer, U. K., Moszner, N. \& Liska, R. New Photocleavable Structures. Diacylgermane-Based Photoinitiators for Visible Light Curing. Macromolecules 41, 2394-2400 (2008).

110. Moad, G. RAFT (Reversible addition-fragmentation chain transfer) crosslinking (co)polymerization of multi-olefinic monomers to form polymer networks. Polym. Int. 64, $15-24(2015)$.

111. Beers, K. L. \& Matyjaszewski, K. The atom transfer radical polymerization of lauryl acrylate. J. Macromol. Sci. Part A 38, 731-739 (2001). 
112. Qin, S., Saget, J., Pyun, J., Jia, S. \& Kowalewski, T. Synthesis of Block, Statistical, and Gradient Copolymers from Octadecyl (Meth)acrylates Using Atom Transfer Radical Polymerization. Macromolecules 36, 8969-8977 (2003).

113. Jakubowski Wojciech, Lutz Jean-François, Slomkowski Stanislaw \& Matyjaszewski Krzysztof. Block and random copolymers as surfactants for dispersion polymerization. I. Synthesis via atom transfer radical polymerization and ring-opening polymerization. $J$. Polym. Sci. Part Polym. Chem. 43, 1498-1510 (2005).

114. Matyjaszewski, K., Patten, T. E. \& Xia, J. Controlled/“Living” Radical Polymerization. Kinetics of the Homogeneous Atom Transfer Radical Polymerization of Styrene. J. Am. Chem. Soc. 119, 674-680 (1997).

115. Liénafa, L., Monge, S. \& Robin, J.-J. A versatile synthesis of poly(lauryl acrylate) using $\mathrm{N}$-(n-octyl)-2-pyridylmethanimine in copper mediated living radical polymerization. Eur. Polym. J. 45, 1845-1850 (2009).

116. Raghunadh, V., Baskaran, D. \& Sivaram, S. Efficiency of ligands in atom transfer radical polymerization of lauryl methacrylate and block copolymerization with methyl methacrylate. Polymer 45, 3149-3155 (2004).

117. Street G., Illsley D. \& Holder S. J. Optimization of the synthesis of poly(octadecyl acrylate) by atom transfer radical polymerization and the preparation of all comblike amphiphilic diblock copolymers. J. Polym. Sci. Part Polym. Chem. 43, 1129-1143 (2005).

118. Chatterjee, D. P. \& Mandal, B. M. Triblock Thermoplastic Elastomers with Poly(lauryl methacrylate) as the Center Block and Poly(methyl methacrylate) or Poly( tert -butyl methacrylate) as End Blocks. Morphology and Thermomechanical Properties. Macromolecules 39, 9192-9200 (2006). 
119. Çayli, G. \& Meier, M. A. R. Polymers from renewable resources: Bulk ATRP of fatty alcohol-derived methacrylates. Eur. J. Lipid Sci. Technol. 110, 853-859 (2008).

120. Dutertre, F., Pennarun, P.-Y., Colombani, O. \& Nicol, E. Straightforward synthesis of poly(lauryl acrylate)-b-poly(stearyl acrylate) diblock copolymers by ATRP. Eur. Polym. J. 47, 343-351 (2011).

121. Xu Youyong et al. Double-Grafted Cylindrical Brushes: Synthesis and Characterization of Poly(lauryl methacrylate) Brushes. Macromol. Chem. Phys. 208, $1666-1675$ (2007).

122. Perrier, S. 50th Anniversary Perspective: RAFT Polymerization-A User Guide. Macromolecules 50, 7433-7447 (2017).

123. Zhu, J., Zhu, X., Cheng, Z., Lu, J. \& Liu, F. Reversible Addition-Fragmentation Chain-Transfer Polymerization of Octadecyl Acrylate. J. Macromol. Sci. Part A 40, 963975 (2003).

124. Gupta, J., Keddie, D. J., Wan, C., Haddleton, D. M. \& McNally, T. Functionalisation of MWCNTs with poly(lauryl acrylate) polymerised by $\mathrm{Cu}(0)$-mediated and RAFT methods. Polym. Chem. 7, 3884-3896 (2016).

125. Demetriou, M. \& Krasia-Christoforou, T. Synthesis and characterization of well-defined block and statistical copolymers based on lauryl methacrylate and 2-(acetoacetoxy)ethyl methacrylate using RAFT-controlled radical polymerization. $J$. Polym. Sci. Part Polym. Chem. 46, 5442-5451 (2008).

126. Semsarilar, M., Penfold, N. J. W., Jones, E. R. \& Armes, S. P. Semi-crystalline diblock copolymer nano-objects prepared via RAFT alcoholic dispersion polymerization of stearyl methacrylate. Polym. Chem. 6, 1751-1757 (2015).

127. Boschmann, D. \& Vana, P. Z-RAFT Star Polymerizations of Acrylates: Star Coupling via Intermolecular Chain Transfer to Polymer. Macromolecules 40, 2683-2693 (2007). 
128. Derry, M. J., Fielding, L. A. \& Armes, S. P. Industrially-relevant polymerizationinduced self-assembly formulations in non-polar solvents: RAFT dispersion polymerization of benzyl methacrylate. Polym Chem 6, 3054-3062 (2015).

129. Roy, D. et al. Synthesis and characterization of transferrin-targeted chemotherapeutic delivery systems prepared via RAFT copolymerization of high molecular weight PEG macromonomers. Polym. Chem. 5, 1791-1799 (2014).

130. Krivorotova, T., Udrènaitè, E., Gromadzki, D. \& Makuška, R. Synthesis of amphiphilic diblock copolymer brushes by successive RAFT polymerization of lauryl methacrylate and PEO-containing macromonomer. 21, 63-71 (2010).

131. Fielding, L. A., Lane, J. A., Derry, M. J., Mykhaylyk, O. O. \& Armes, S. P. Thermoresponsive Diblock Copolymer Worm Gels in Non-polar Solvents. J. Am. Chem. Soc. 136, 5790-5798 (2014).

132. Ratcliffe, L. P. D. et al. Polymerization-Induced Self-Assembly of All-Acrylic Diblock Copolymers via RAFT Dispersion Polymerization in Alkanes. Macromolecules 48, 8594-8607 (2015).

133. Feng, Y. \& Xiao, C. F. Research on butyl methacrylate-lauryl methacrylate copolymeric fibers for oil absorbency. J. Appl. Polym. Sci. 101, 1248-1251 (2006).

134. Chatterjee, D. P. \& Mandal, B. M. Triblock Thermoplastic Elastomers with Poly(lauryl methacrylate) as the Center Block and Poly(methyl methacrylate) or Poly(tertbutyl methacrylate) as End Blocks. Morphology and Thermomechanical Properties. Macromolecules 39, 9192-9200 (2006).

135. Krivorotova, T., Vareikis, A., Gromadzki, D., Netopilík, M. \& Makuška, R. Conventional free-radical and RAFT copolymerization of poly(ethylene oxide) containing macromonomers. Eur. Polym. J. - EUR POLYM J 46, 546-556 (2010). 
136. Das, D. et al. Synthesis of zwitterionic, hydrophobic, and amphiphilic polymers via RAFT polymerization induced self-assembly (PISA) in acetic acid. Polym Chem 7, 6133$6143(2016)$.

137. Huang, J. et al. Synthesis of Triblock Copolymers via RAFT Polymerization and Their Application as Surfactants for Crude Oil-in-Water Emulsion. Ind. Eng. Chem. Res. 54, 1564-1575 (2015).

138. Liu, Y. et al. Sustainable thermoplastic elastomers derived from renewable cellulose, rosin and fatty acids. Polym. Chem. 5, 3170 (2014).

139. Pei, Y., Thurairajah, L., Sugita, O. R. \& Lowe, A. B. RAFT Dispersion Polymerization in Nonpolar Media: Polymerization of 3-Phenylpropyl Methacrylate in $n$ Tetradecane with Poly(stearyl methacrylate) Homopolymers as Macro Chain Transfer Agents. Macromolecules 48, 236-244 (2015).

140. Maiti, B., Maiti, S. \& De, P. Self-assembly of well-defined fatty acid based amphiphilic thermoresponsive random copolymers. RSC Adv 6, 19322-19330 (2016).

141. Maiti, B., Haldar, U., Rajasekhar, T. \& De, P. Functional-Polymer Library through Post-Polymerization Modification of Copolymers Having Oleate and Pentafluorophenyl Pendants. Chem. - Eur. J. 23, 15156-15165

142. Jena, S. S., Roy, S. G., Azmeera, V. \& De, P. Solvent-dependent self-assembly behaviour of block copolymers having side-chain amino acid and fatty acid block segments. React. Funct. Polym. 99, 26-34 (2016).

143. Anderson, J. E., Kim, B. R., Mueller, S. A. \& Lofton, T. V. Composition and Analysis of Mineral Oils and Other Organic Compounds in Metalworking and Hydraulic Fluids. Crit. Rev. Environ. Sci. Technol. 33, 73-109 (2003).

144. Moad, G., Rizzardo, E. \& Thang, S. H. Living Radical Polymerization by the RAFT Process - A Second Update. Aust. J. Chem. 62, 1402 (2009). 
145. Perrier, S., Takolpuckdee, P. \& Mars, C. A. Reversible Addition-Fragmentation Chain Transfer Polymerization: End Group Modification for Functionalized Polymers and Chain Transfer Agent Recovery. Macromolecules 38, 2033-2036 (2005).

146. Tiwari, A., Galanis, A. \& Soucek, M. D. Biobased and Environmentally Benign Coatings. (John Wiley \& Sons, 2016).

147. International, A. S. M. \& Lampman, S. Characterization and Failure Analysis of Plastics. (ASM International, 2003).

148. Czech, Z. \& Milker, R. Development trends in pressure-sensitive adhesive systems. Mater.-Sci. Pol. 23, 1016-1022 (2005).

149. Webster, I. Recent developments in pressure-sensitive adhesives for medical applications. Int. J. Adhes. Adhes. 17, 69-73 (1997).

150. Maaßen, W. et al. Novel Insights into Pressure-Sensitive Adhesives Based on Plant Oils. Macromol. Chem. Phys. 216, 1609-1618 (2015).

151. Ghosh, P., Hoque, M., Karmakar, G. \& Das, M. K. Dodecyl methacrylate and vinyl acetate copolymers as viscosity modifier and pour point depressant for lubricating oil. Int. J. Ind. Chem. 8, 197-205 (2017).

152. Mohamad, S. A., Ahmed, N. S., Hassanein, S. M. \& Rashad, A. M. Investigation of polyacrylates copolymers as lube oil viscosity index improvers. J. Pet. Sci. Eng. 100, 173-177 (2012).

153. Ghosh, P. Evaluation of acrylate-sunflower oil copolymer as viscosity index improvers for lube oils. J. Chem. Pharm. Res. 547-556 (2011).

154. Al-Sabagh, A. M., El-Hamouly, S. H., Khidr, T. T., El-Ghazawy, R. A. \& Higazy, S. A. Preparation the Esters of Oleic Acid-Maleic Anhydride Copolymer and Their Evaluation as Flow Improvers for Waxy Crude Oil. J. Dispers. Sci. Technol. 34, 15851596 (2013). 
155. Neveu, C. D., Sondjaja, R., Stöhr, T. \& Iroff, N. J. Lubricant and Fuel Additives Based on Polyalkylmethacrylates. in Polymer Science: A Comprehensive Reference 453478 (Elsevier, 2012). doi:10.1016/B978-0-444-53349-4.00277-6

156. Yang, F., Zhao, Y., Sjöblom, J., Li, C. \& Paso, K. G. Polymeric Wax Inhibitors and Pour Point Depressants for Waxy Crude Oils: A Critical Review. J. Dispers. Sci. Technol. 36, 213-225 (2015).

157. Martini, A., Ramasamy, U. S. \& Len, M. Review of Viscosity Modifier Lubricant Additives. Tribol. Lett. 66, 58 (2018).

158. Behbahani, T. J. Experimental Investigation of the Polymeric flow improver on Waxy oils. Pet. Coal 56, 139-142 (2014).

159. Soni, H. P. \& Bharambe, D. P. Synthesis and evaluation of polymeric additives as flow improvers for Indian crude oil. Iran. Polym. J. 15, 943 (2006).

160. Lomège, J., Negrell, C., Robin, J.-J., Lapinte, V. \& Caillol, S. Fatty acid-Based Methacrylate Polymers as Viscosity Modifiers for Mineral Oils. Green Mater. 1-46 (2018). doi:10.1680/jgrma.18.00014

161. Selby, T. W. The Non-Newtonian Characteristics of Lubricating Oils. E Trans. 1, 6881 (1958).

162. Wang, S., Ding, W., Yang, G. \& Robertson, M. L. Biorenewable Thermoplastic Elastomeric Triblock Copolymers Containing Salicylic Acid-Derived End-Blocks and a Fatty Acid-Derived Midblock. Macromol. Chem. Phys. 217, 292-303 (2015).

163. Jeusette, M. et al. New "All-Acrylate" Block Copolymers: Synthesis and Influence of the Architecture on the Morphology and the Mechanical Properties. Macromolecules 40, 1055-1065 (2007). 
164. Tong, J. D. \& Jerôme, R. Synthesis of poly(methyl methacrylate)-b-poly(n-butyl acrylate)-b-poly(methyl methacrylate) triblocks and their potential as thermoplastic elastomers. Polymer 41, 2499-2510 (2000).

165. Wang, S., Vajjala Kesava, S., Gomez, E. D. \& Robertson, M. L. Sustainable Thermoplastic Elastomers Derived from Fatty Acids. Macromolecules 46, 7202-7212 (2013).

166. Zhu, X., Gu, Y., Chen, G., Cheng, Z. \& Lu, J. Synthesis of poly(octadecyl acrylate-b-styrene-b-octadecyl acrylate) triblock copolymer by atom transfer radical polymerization. J. Appl. Polym. Sci. 93, 1539-1545 (2004).

167. Rogers, S. \& Mandelkern, L. Glass Transitions of the Poly-(n-Alkyl Methacrylates). J. Phys. Chem. 61, 985-991 (1957).

168. Jiang, F., Wang, Z., Qiao, Y., Wang, Z. \& Tang, C. A Novel Architecture toward Third-Generation Thermoplastic Elastomers by a Grafting Strategy. Macromolecules 46, 4772-4780 (2013).

169. Yu, J. et al. Sustainable thermoplastic elastomers derived from cellulose, fatty acid and furfural via ATRP and click chemistry. Carbohydr. Polym. 176, 83-90 (2017).

170. Warren, N. J., Mykhaylyk, O. O., Mahmood, D., Ryan, A. J. \& Armes, S. P. RAFT Aqueous Dispersion Polymerization Yields Poly(ethylene glycol)-Based Diblock Copolymer Nano-Objects with Predictable Single Phase Morphologies. J. Am. Chem. Soc. 136, 1023-1033 (2014).

171. Hanisch, A. et al. Phosphonic Acid-Functionalized Diblock Copolymer Nano-Objects via Polymerization-Induced Self-Assembly: Synthesis, Characterization, and Occlusion into Calcite Crystals. Macromolecules 49, 192-204 (2016). 
172. Datta, L. P., De, D., Ghosh, U. \& Das, T. K. RAFT derived fatty acid based stimuli responsive fluorescent block copolymers as DNA sensor and cargo delivery agent. Polymer 138, 103-112 (2018). 


\section{For Table of Contents Only}

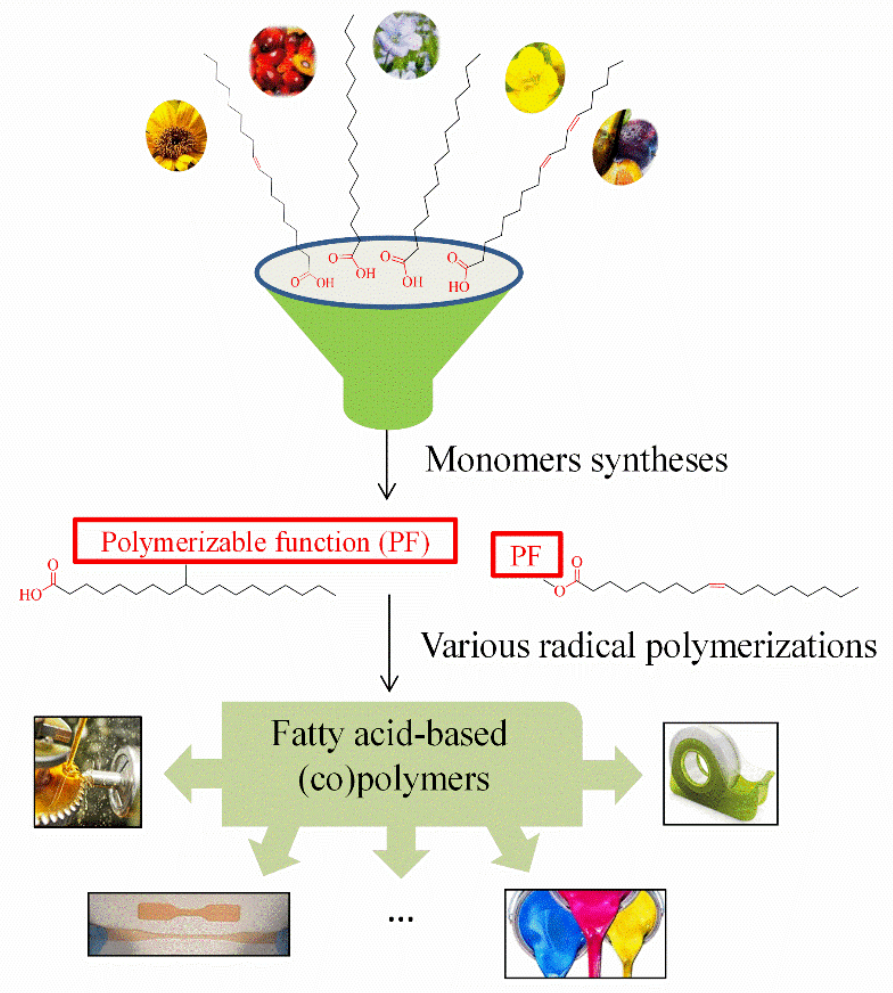

